\title{
ON THE DRIVING PROCESSES OF THE ATLANTIC MERIDIONAL OVERTURNING CIRCULATION
}

\author{
T. Kuhlbrodt, ${ }^{1}$ A. Griesel, ${ }^{2}$ M. Montoya, ${ }^{3}$ A. Levermann, ${ }^{1}$ M. Hofmann, ${ }^{1}$ and S. Rahmstorf ${ }^{1}$ \\ Received 3 December 2004; revised 10 August 2006; accepted 26 October 2006; published 24 April 2007.
}

[1] Because of its relevance for the global climate the Atlantic meridional overturning circulation (AMOC) has been a major research focus for many years. Yet the question of which physical mechanisms ultimately drive the $\mathrm{AMOC}$, in the sense of providing its energy supply, remains a matter of controversy. Here we review both observational data and model results concerning the two main candidates: vertical mixing processes in the ocean's interior and windinduced Ekman upwelling in the Southern Ocean. In distinction to the energy source we also discuss the role of surface heat and freshwater fluxes, which influence the volume transport of the meridional overturning circulation and shape its spatial circulation pattern without actually supplying energy to the overturning itself in steady state. We conclude that both wind-driven upwelling and vertical mixing are likely contributing to driving the observed circulation. To quantify their respective contributions, future research needs to address some open questions, which we outline.

Citation: Kuhlbrodt, T., A. Griesel, M. Montoya, A. Levermann, M. Hofmann, and S. Rahmstorf (2007), On the driving processes of the Atlantic meridional overturning circulation, Rev. Geophys., 45, RG2001, doi:10.1029/2004RG000166.

\section{INTRODUCTION}

[2] The deep Atlantic meridional overturning circulation (AMOC) consists of four main branches: upwelling processes that transport volume from depth to near the ocean surface, surface currents that transport relatively light water toward high latitudes, deepwater formation regions where waters become denser and sink, and deep currents closing the loop. These four branches span the entire Atlantic on both hemispheres, forming a circulation system that consists of two overturning cells, a deep one with North Atlantic Deep Water (NADW) and an abyssal one with Antarctic Bottom Water (AABW). A highly simplified, illustrative sketch of this circulation is given in Figure 1. The AMOC exerts a strong control on the stratification and distribution of water masses, the amount of heat that is transported by the ocean, and the cycling and storage of chemical species such as carbon dioxide in the deep sea. Thus the AMOC is a key player in the Earth's climate. In the North Atlantic its maximum northward heat transport is about $1 \mathrm{PW}\left(10^{15} \mathrm{~W}\right)$ [Hall and Bryden, 1982; Ganachaud and Wunsch, 2000; Trenberth and Caron, 2001], contributing to the mild climate predominant in northwestern Europe. A reduction in AMOC is likely to have strong implications for the

\footnotetext{
${ }^{1}$ Potsdam Institute for Climate Impact Research, Potsdam, Germany.

${ }^{2}$ Scripps Institution of Oceanography, La Jolla, California, USA.

${ }^{3}$ Departamento Astrofisica y Ciencias de la Atmósfera, Facultad de Ciencias Físicas, Universidad Complutense de Madrid, Madrid, Spain.
}

El Niño-Southern Oscillation phenomenon [Timmermann et al., 2005], the position of the Intertropical Convergence Zone [Vellinga and Wood, 2002], the marine ecosystem in the Atlantic [Schmittner, 2005], and the sea level in the North Atlantic [Levermann et al., 2005]. Evidence from the geological past [Bond et al., 1992; McManus et al., 2004] suggests that reorganizations of the AMOC were involved in climatic temperature changes of several degrees in a few decades (see also the reviews by Clark et al. [2002] and Rahmstorf [2002]). In the future, there is a risk that substantial changes in ocean circulation could occur as a result of global warming [Manabe and Stouffer, 1994; Rahmstorf and Ganopolski, 1999; Wood et al., 1999; Schaeffer et al., 2002; Zickfeld et al., 2007].

[3] Ultimately, the influence of Sun and Moon is responsible for oceanic and atmospheric circulations on Earth. The surface fluxes of heat, fresh water, and momentum as well as gravity and tides set the ocean waters in motion, either directly or via intermediate processes such as waves. The main aim of this paper is to discuss the physical mechanisms that drive the AMOC in the sense that they provide an energy input into the ocean that is capable of sustaining a steady state deep overturning circulation.

[4] Presently, two distinct mechanisms for driving the meridional overturning circulation (MOC) are discussed. The first one is the traditional thermohaline driving mechanism proposed by Sandström [1916] and Jeffreys [1925]. In this view the driver is mixing that transports heat from the surface to the deepwater masses, downward across 

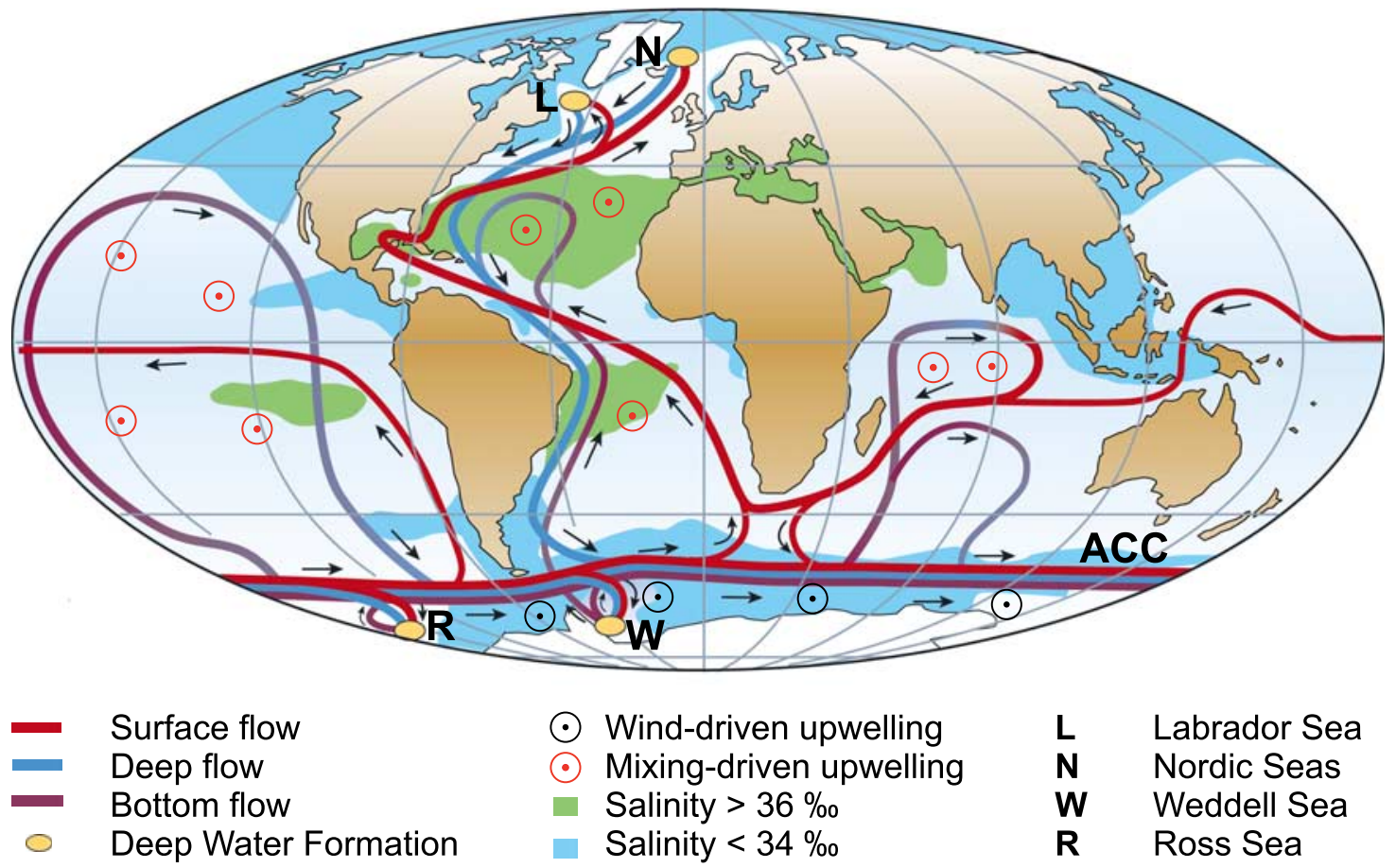

Figure 1. Strongly simplified sketch of the global overturning circulation system. In the Atlantic, warm and saline waters flow northward all the way from the Southern Ocean into the Labrador and Nordic Seas. By contrast, there is no deepwater formation in the North Pacific, and its surface waters are fresher. Deep waters formed in the Southern Ocean become denser and thus spread in deeper levels than those from the North Atlantic. Note the small, localized deepwater formation areas in comparison with the widespread zones of mixing-driven upwelling. Wind-driven upwelling occurs along the Antarctic Circumpolar Current (ACC). After Rahmstorf [2002].

surfaces of equal density (diapycnal mixing). Munk and Wunsch [1998] described this mechanism in detail. The action of winds and tides generates internal waves in the oceans. These waves dissipate into small-scale motion that causes turbulent mixing. This mixing of heat lightens water masses in the deep ocean and causes them to rise in low latitudes. Resulting surface and intermediate waters are then advected poleward into the North Atlantic where they are transformed into dense waters by atmospheric cooling and salt rejection during sea ice growth. These waters sink to depth and spread, setting up the deepwater mass of the ocean. Thereby a meridional density gradient between high and low latitudes is established. A sketch of the involved processes and their locations is given in Figure 2.

[5] The second candidate is wind-driven upwelling, as put forward by Toggweiler and Samuels [1993b, 1995, 1998]. On the basis of observational radiocarbon constraints they concluded that the actual amount of upwelling of abyssal water caused by diapycnal mixing is insufficient to sustain an estimated overturning of about $15 \mathrm{~Sv}(1 \mathrm{~Sv}=1$ Sverdrup $=10^{6} \mathrm{~m}^{3} \mathrm{~s}^{-1}$ ) in the Atlantic Ocean. As an alternative they suggested that most of the oceanic upwelling is wind-driven and occurs in the Southern Ocean. The strong westerly circumpolar winds induce a vigorous northward transport of waters, called Ekman transport, near the ocean surface. Since there is a horizontal divergence of the
Ekman transport, an upwelling from depth is induced that is associated with the so-called Drake Passage effect (see Figure 2). In this view it is the strength of Southern Ocean winds rather than the oceanic diapycnal mixing that governs the strength of the AMOC. Note that in this theory the winds induce large-scale motion of the water masses in the Southern Ocean, which enter the Atlantic and flow to the northern deepwater formation sites. Wind-driven mixing, i.e., small-scale turbulent motion that is induced by surface wind stress, is part of the mixing processes and is not considered as a direct wind-driven upwelling.

[6] Determining which of these two processes is the main driving mechanism of the MOC is of great interest, even beyond the mere aim of physical understanding. The two could imply different sensitivities to variations in external forcing [Schmittner and Weaver, 2001; Prange et al., 2003] and thus a different evolution of the MOC under continued global climate change. In the present paper we review work on theory, modeling, and observations that argue for either or both of the possible driving mechanisms.

[7] We wish to emphasize that the driving processes do not fully determine the AMOC's spatial extent and strength. The amount of water that actually sinks in the North Atlantic is controlled by a variety of processes including the horizontal gyre circulation, atmospheric cooling, precipitation, evaporation, and ice melting. These processes 


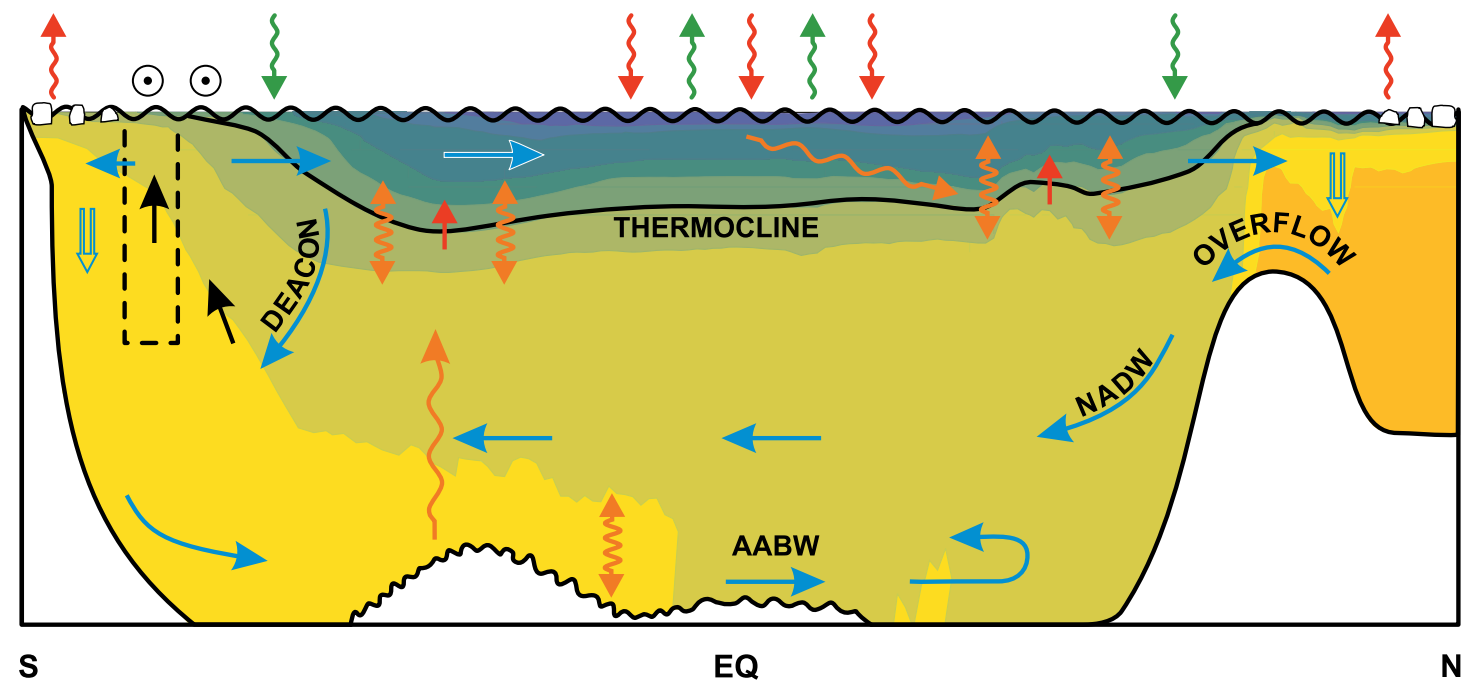

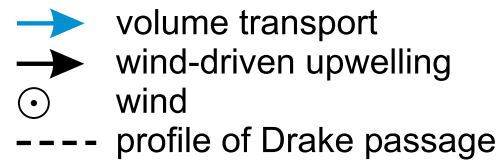

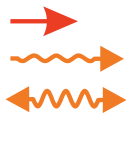

mixing-driven up
internal waves
diapycnal mixing
$\mathbf{N}$

Figure 2. Idealized meridional section representing a zonally averaged picture of the Atlantic Ocean. Straight arrows sketch the MOC. The color shading depicts a zonally averaged density profile derived from observational data [Levitus, 1982]. The thermocline, the region where the temperature gradient is large, separates the light and warm upper waters from the denser and cooler deep waters. The two main upwelling mechanisms, wind-driven and mixing-driven, are displayed. Wind-driven upwelling is a consequence of a northward flow of the surface waters in the Southern Ocean, the Ekman transport, that is driven by strong westerly winds (see section 4). Since the Ekman transport is divergent, waters upwell from depth. Mixing along the density gradient, called diapycnal mixing, causes mixing-driven upwelling; this is partly due to internal waves triggered at the ocean's boundaries (see section 3). Deepwater formation (DWF) occurs in the high northern and southern latitudes, creating North Atlantic Deep Water (NADW) and Antarctic Bottom Water (AABW), respectively. The locations of DWF are tightly linked with the distribution of surface fluxes of heat and fresh water; since these influence the buoyancy of the water, they are subsumed as buoyancy fluxes. The freshly formed NADW has to flow over the shallow sill between Greenland, Iceland, and Scotland. Close to the zone of wind-driven upwelling in the Southern Ocean is the Deacon cell recirculation, visible in the zonally integrated meridional velocity in ocean models. Its relevance is discussed in section 4. Note that in the real ocean the ratio of the meridional extent to the typical depth is about 5000 to 1 .

can change the AMOC's spatial pattern drastically, and they can temporarily reduce or increase the amount of deep water formed, with a strong impact on climate. However, our focus here is on the AMOC as a large-scale coherent circulation system and on longer timescales, that is, on which mechanism provides the ocean with the energy necessary to sustain a steady state deep overturning circulation.

[8] The terms "meridional overturning circulation" and "thermohaline circulation" (THC) have sometimes been used almost like synonyms, but they have very different meanings. "MOC" is merely a descriptive, geographic term: It is simply a circulation in the meridional-vertical plane, as depicted by an overturning stream function as in Figure 3. The term "MOC" thus does not refer to any particular driving mechanism.

[9] The term "THC," by contrast, is a definition of flow by driving mechanism. There are three qualitatively differ- ent physical mechanisms to drive oceanic flows: (1) direct momentum transfer by surface winds, (2) acceleration of water by tidal forces, and (3) thermohaline forcing. This classification has been found in oceanography textbooks since the early 20th century [e.g., Defant, 1929; Neumann and Pierson, 1966]. A simple, archetypal example of the latter would be the regional thermohaline (or, in this case, thermal) circulation caused by "hot spots" of geothermal heating at the ocean bottom near mid-ocean ridges [Joyce and Speer, 1987; Thompson and Johnson, 1996]. Another example is the flow driven by strong surface cooling of a previously warmer body of water, as occurs, for example, when a polynya opens up in sea ice [Buffoni et al., 2002]. In these examples, thermohaline fluxes at the ocean boundary (surface or bottom) cause density changes that drive a flow by setting up pressure gradients.

[10] A complication arises when considering the largescale thermohaline circulation in steady state, as this steady 


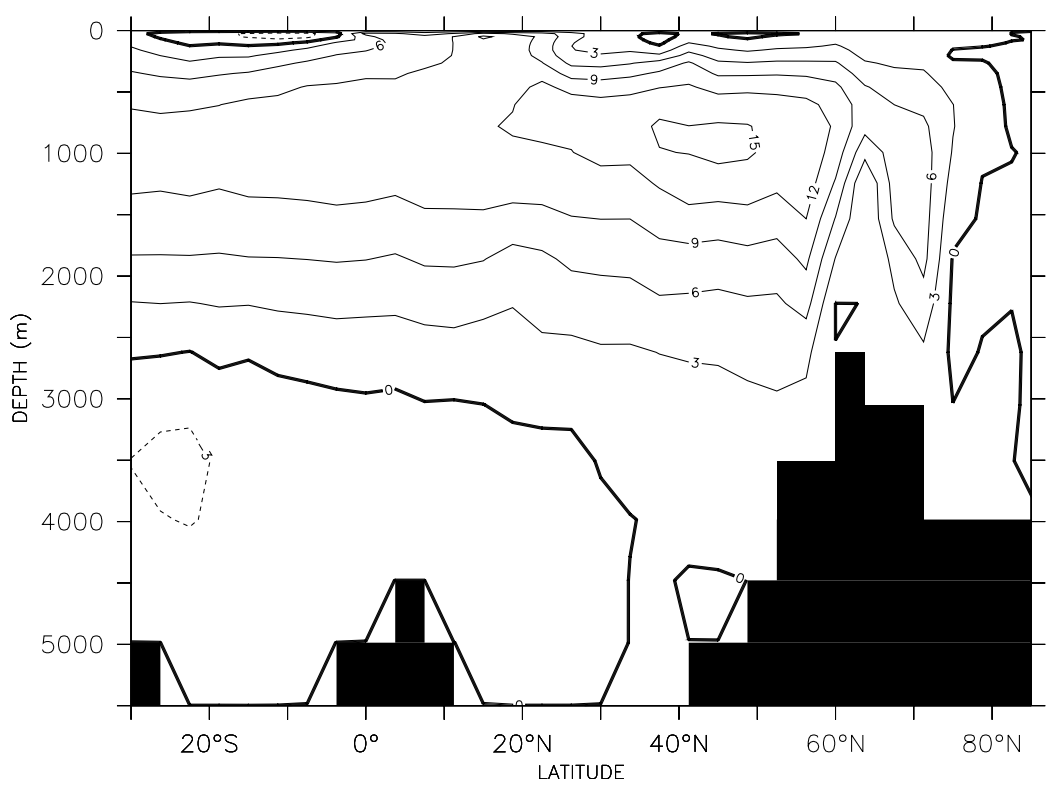

Figure 3. Stream function of the zonally integrated meridional overturning circulation in the Atlantic Ocean, as simulated by a coupled ocean-atmosphere model (for a full description of the model see Montoya et al. [2005]). Contour interval is a fixed volume flux of $3 \mathrm{~Sv}=3 \times 10^{6} \mathrm{~m}^{3} \mathrm{~s}^{-1}$. Solid (dashed) lines indicate a clockwise (a counterclockwise) circulation. While the maximum overturning of the model NADW (at about $40^{\circ} \mathrm{N}$ and $1000 \mathrm{~m}$ depth) is $15.5 \mathrm{~Sv}$, the outflow at $30^{\circ} \mathrm{S}$ is only $9.8 \mathrm{~Sv}$. The model AABW enters the Atlantic with a volume flux of about $3 \mathrm{~Sv}$.

state cannot be maintained by surface buoyancy fluxes alone. As discussed in detail in section 2, a mechanical energy input is required to sustain the turbulence necessary to mix down heat in order to maintain the pressure gradients in addition to the surface fluxes. To account for this fact, the large-scale thermohaline circulation has been defined as "currents driven by fluxes of heat and fresh water across the sea surface and subsequent interior mixing of heat and salt" [Rahmstorf, 2002, p. 208, 2003]. The same fact is addressed by the definition of Huang [2004, p. 497]: [The $\mathrm{THC}$ is] "an overturning flow in the ocean driven by mechanical stirring/mixing, which transports mass, heat, fresh water, and other properties. In addition, the surface heat and freshwater fluxes are necessary for setting up the flow." However, mechanical stirring is only necessary for sustaining a steady state large-scale MOC not for the examples of transient or regional thermohaline flows mentioned above. Being aware that the word "driver" is used with different meanings in the literature, we use it for the remainder of this paper with the meaning "the physical process that provides the necessary energy input to sustain a steady state deep MOC."

[11] Since we discuss both a mechanism to drive the large-scale MOC directly by winds (section 4) and the traditional driving mechanism including turbulent mixing and thermohaline forcing (section 3 ) in this paper, we will generally use the driver-neutral terms "MOC" or "AMOC." We restrict our discussion to the deep MOC, excluding the shallow Ekman cells of the MOC that are usually confined to the upper few hundred meters.
[12] The paper is organized as follows. Section 2 deals with "Sandström's theorem." On the basis of experiments and theory it implies that the steady state MOC cannot be driven by surface buoyancy fluxes alone. We present the critical discussion that has followed the early statement of this theorem. A focus is put on the energy budget of the general circulation. Subsequently, the two possible driving mechanisms are presented. Diapycnal mixing as a driver is discussed in section 3, centered around the budget of turbulent diapycnal mixing energy and its sources, which are basically winds and tides. In addition, we treat the fundamental difficulties of representing turbulent mixing in ocean general circulation models. Surface wind forcing as a driver is addressed in section 4. This includes tracer evidence for wind-driven upwelling in the Southern Ocean and a specific dynamical constraint favoring this upwelling. Section 4 ends with a revisit to the budget of turbulent diapycnal mixing energy. We find that likely both mixing and wind-driven upwelling drive the AMOC. Next, in section 5 we study the role of the surface buoyancy fluxes in setting the strength and the shape of the AMOC; today's AMOC is characterized by deepwater formation in the northern North Atlantic and the Southern Ocean. A question of strong interest is the stability of the AMOC, to which we devote section 6. Specific issues are the AMOC's instabilities in past climates and various sources of bistability, like freshwater fluxes or the different driving mechanisms. A reason for concern in the near future are transient changes of the AMOC along with their consequences. In section 7 we 
a)

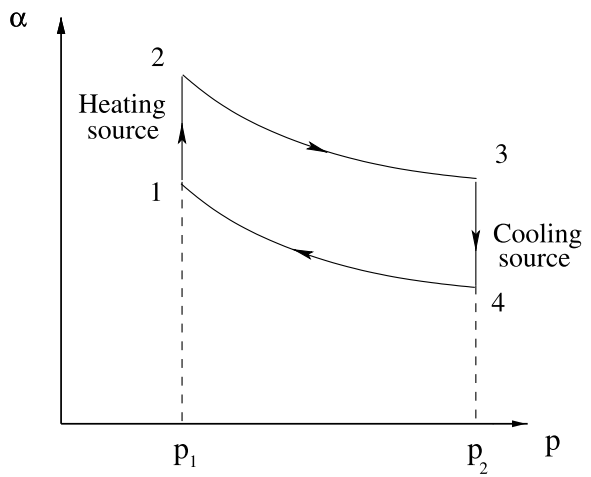

b)

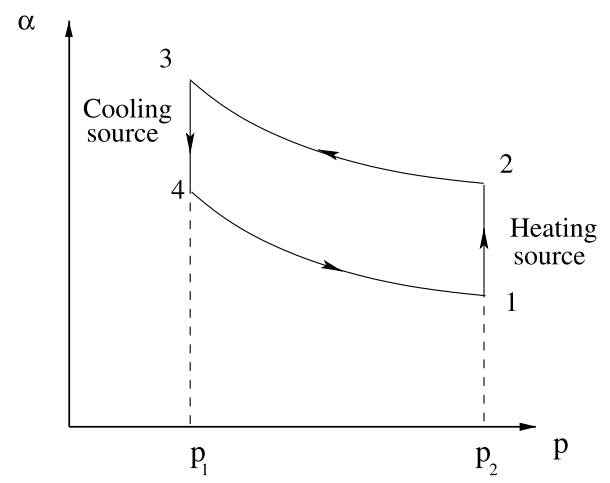

Figure 4. Idealized Carnot cycle for the ocean, as proposed by Sandström [1916] [after Defant, 1961]: (a) heating source at lower pressure (smaller depth) than cooling source and (b) heating source at higher pressure (larger depth) than cooling source. Here $p$ is pressure; $\alpha$ is specific volume.

summarize the central results and outline the main open questions.

\section{ENERGY BUDGET AND SANDSTRÖM'S THEOREM}

[13] As we will see in sections 3 and 4, the question of which mechanisms drive the AMOC is intimately linked to where and how the upwelling of deep water takes place. The ocean's mechanical energy is continuously dissipated through friction. To maintain a steady state circulation, an energy source is required to overcome friction. Identifying such a process, its role in the energy budget of the ocean, and the energy pathways has been the subject of substantial research in the past decade [e.g., Munk and Wunsch, 1998; Toggweiler and Samuels, 1998; Huang, 1999; Gade and Gustafsson, 2004; Huang, 2004; Wunsch and Ferrari, 2004; Gnanadesikan et al., 2005]. Our intention herein is to review the current understanding.

\subsection{Sandström's Theorem}

[14] The starting point of discussions on energetics of the ocean and the drivers of the ocean's overturning circulation is often what is commonly known as Sandström's theorem [e.g., Defant, 1961; Dutton, 1986; Houghton, 1986; Colin de Verdière, 1993; Munk and Wunsch, 1998; Huang, 1999; Gade and Gustafsson, 2004; Huang, 2004; Wunsch and Ferrari, 2004; Gnanadesikan et al., 2005; Hughes and Griffiths, 2006]. Sandström [1908] performed a series of tank experiments in which he analyzed under which conditions buoyancy forcing alone, applied at different depths, could lead to a deep overturning circulation in a water tank. A heating and a cooling source were placed at opposite extremes in the tank. In one of the experiments the heating source was situated above the cooling source; in another one it was below. Sandström [1908] concluded that a thermally driven, closed, steady circulation in the ocean can only be established if the heating source is situated at a lower level than the cooling source.
[15] Sandström's theorem was later put on a more theoretical foundation by Sandström [1916] and Bjerknes [1916]. Neglecting the Earth's rotation, the forces acting upon a fluid parcel are pressure gradient forces, gravity, and friction. The circulation equation along a closed streamline $S$ thus gives [Defant, 1961]:

$$
\begin{aligned}
\frac{d C}{d t} & =\frac{d}{d t} \oint_{S} \mathbf{u} \cdot d \mathbf{r}=\oint_{S} \frac{d \mathbf{u}}{d t} \cdot d \mathbf{r} \\
& =-\oint_{S} \alpha d p+\oint_{S} \mathbf{F} \cdot d \mathbf{r}+\oint_{S} \mathbf{g} \cdot d \mathbf{r}
\end{aligned}
$$

where $t$ is time, $\mathbf{u}$ is the velocity, $\alpha$ is the specific volume ( $\alpha=$ $\rho^{-1}$, where $\rho$ is the density), $p$ is the pressure, $\mathbf{F}$ is the friction force per unit mass, and $d \mathbf{r}$ is a distance element along the streamline. Because $\mathbf{g}=-\boldsymbol{\nabla} \phi$, the last term of the right-hand side vanishes. The two remaining terms on the right-hand side represent the work done by pressure gradient forces and the dissipation of energy through friction, respectively. In steady state,

$$
\frac{d C}{d t}=-\oint_{S} \alpha d p+\oint_{S} \mathbf{F} \cdot d \mathbf{r}=0
$$

that is, pressure gradient forces must do work against friction in order to balance frictional energy dissipation. Any extra positive work by pressure gradient forces will contribute to accelerate the fluid.

[16] Sandström [1916] (see also the discussions by Defant [1961] and Huang [1999]) considered a Carnot cycle, consisting of two isobars $(d p=0)$ and two adiabatic curves operating between a heating and a cooling source (Figure 4). In the first case the heating source is located at a lower pressure than the cooling source, and the cycle takes place clockwise. The system is heated from 1 to 2 and expands at constant pressure $p_{1}$. At 2 the heating source is removed, and the system is adiabatically compressed from 2 to 3 . From 3 to 4 a cooling source is applied, and the system 
TABLE 1. Energy Sources ${ }^{a}$

\begin{tabular}{|c|c|c|c|}
\hline Energy Source & Term & $\begin{array}{l}\text { Estimate, } \\
\text { TW }\end{array}$ & Reference \\
\hline Geothermal heating & & 0.05 & Huang [1999] \\
\hline Surface heat fluxes ${ }^{b}$ & & 0.0015 & $\begin{array}{l}\text { Wang and } \\
\text { Huang [2005] }\end{array}$ \\
\hline \multirow[t]{3}{*}{ Winds $^{\mathrm{c}}$} & $\tau \cdot \mathbf{u}_{\mathbf{o}, \mathbf{g}}$ & 1 & Wunsch [1998] \\
\hline & $\tau \cdot \mathbf{u}_{\mathbf{o}, \mathbf{a}}$ & 3 & $\begin{array}{l}\text { Wang and } \\
\text { Huang [2004a] }\end{array}$ \\
\hline & $\overline{\mathbf{t}^{\prime} \cdot \mathbf{u}_{\mathbf{o}}^{\prime}}+\overline{p^{\prime} w_{o}^{\prime}}$ & 60 & $\begin{array}{l}\text { Wang and } \\
\text { Huang [2004b] }\end{array}$ \\
\hline Tides & & 3.5 & $\begin{array}{l}\text { Munk and } \\
\text { Wunsch [1998] }\end{array}$ \\
\hline
\end{tabular}

${ }^{\mathrm{a}}$ From all sources together, about 2 TW are available for turbulent mixing at depth. Most of these 2 TW are, however, dissipated by viscous friction. Only 0.4 TW, an uncertain estimate, is actually available for diapycnal mixing.

${ }^{\mathrm{b}}$ Only part of the total surface heat fluxes is converted into mechanical energy.

${ }^{\mathrm{c}}$ Here $\boldsymbol{\tau} \cdot \mathbf{u}_{\mathbf{o}, \mathbf{g}}$ represents the work by the wind stress on the large-scale geostrophic flow, and $\tau \cdot \mathbf{u}_{\mathbf{o}, \mathbf{a}}$ is the work by the wind stress on the largescale ageostrophic flow; $\overline{\mathbf{t}^{\prime} \cdot \mathbf{u}_{\mathrm{o}}^{\prime}}+\overline{p^{\prime} w_{o}^{\prime}}$ is the work by the winds on the surface waves.

is compressed at a pressure $p_{2}$. At 4 the cooling source is removed, and the system expands adiabatically back to 1 . Thus the first term of the right-hand side in equation (2) is

$$
-\oint_{S} \alpha d p=-\int_{p_{1}}^{p_{2}}\left(\alpha_{2 \rightarrow 3}-\alpha_{4 \rightarrow 1}\right) d p<0
$$

that is, pressure forces cannot do any work. In the second case the heat source is located at a higher pressure than the cold source, and the cycle takes place counterclockwise. In this case,

$$
-\oint_{S} \alpha d p=-\int_{p_{1}}^{p_{2}}\left(\alpha_{4 \rightarrow 1}-\alpha_{2 \rightarrow 3}\right) d p>0 .
$$

Thus work by the pressure forces against frictional forces will be produced only if heating (expansion) takes place at a larger pressure (i.e., depth) than cooling (compression), as concluded by Sandström [1908, 1916]. This implies that heat flowing into the system is converted into work; that is, the system behaves as a heat engine. The same conclusion was drawn from studying Sandström's theorem in the framework of a thermohaline loop model [Wunsch, 2005].

[17] To explain the MOC in the ocean, we need to identify heat sources at depth (if other external forcings, like winds, are absent). The ocean is heated at the tropics and cooled at high latitudes at the surface, with the tropical sea surface about $1 \mathrm{~m}$ higher, and thus at lower pressure, than the high-latitude sea surface. This corresponds to the first case above: With this distribution of the surface heat fluxes the ocean is not a heat engine. The next possible source is solar radiation. It penetrates some $100 \mathrm{~m}$ into the ocean's interior, depending on the radiation frequency and the sea state, including some of the biological indices [e.g., Morel and Antoine, 1994], but the associated energy source is of only about $0.01 \mathrm{TW}\left(1 \mathrm{TW}=10^{12} \mathrm{~W}\right)$ [Huang and Wang, 2003]. Hence, according to Sandström's theorem one should expect at most a shallow circulation, confined between the sea surface and the depth of penetration of solar radiation [Wunsch and Ferrari, 2004]. Moreover, the associated conversion rate to mechanical energy is only 0.0015 TW [Wang and Huang, 2005] (see also Table 1). Another source of heat at depth is geothermal heating. Yet the implied energy source, about $0.05 \mathrm{TW}$, is too weak to have a significant impact in the ocean's circulation [Huang, 1999] (Table 1). Obviously, there must be other heat sources at depth. This conclusion was already drawn by Sandström himself. He proposed turbulent mixing of heat at low latitudes to transport heat downward. However, his idea that salinity-driven convection could power the required low-latitude mixing is not feasible. Jeffreys [1925] pointed out that in Sandström's experiments the only means to redistribute heat is conduction and that Sandström's theorem does not take into account turbulent diffusion. Jeffreys [1925] showed that when turbulent diffusion is included any horizontal density gradient induces a circulation, even if the heating source is at a higher level than the cooling source. Thus he questioned the validity of Sandström's theorem for the atmospheric circulation, in which turbulence is always present, but recognized its possible relevance for the ocean circulation, for which, he assumed, turbulence is confined to the surface neighborhood. As pointed out by Munk and Wunsch [1998], neither Sandström nor Jeffreys knew of the existence of vigorous convective motions in the ocean. The same applies to turbulent mixing in the ocean interior, in particular diapycnal mixing, which, because the ocean stratification is almost everywhere vertical, allows for the penetration of heat into the deep ocean.

[18] Using a loop model, Huang [1999] showed that when turbulent mixing is taken into account and the heat source is located at a higher level than the cooling source, the strength of the circulation is controlled by the energy available for mixing. As explained by Huang [1999] (see section 3), in a stratified ocean, diapycnal mixing raises the center of mass of the system and thereby its gravitational potential energy (GPE). Thus an external mechanical source of energy is required to sustain mixing.

[19] While in laboratory experiments a deep flow may be driven by surface heat fluxes and molecular mixing, such that external energy sources are not necessary (see section 2.3), for the oceanic MOC we conclude that the surface buoyancy fluxes do not drive the flow. The ocean is indeed heated and cooled at the surface, with the heating and cooling sources roughly at the same depth, but heating and cooling are not the sole forcing. The ocean is forced at its surface by atmospheric winds and through its volume by tides. Winds and tides result in turbulent mixing capable of driving the flow [Colin de Verdière, 1993; Munk and Wunsch, 1998; Huang, 1999]. In addition, the wind forcing directly contributes to the large-scale kinetic energy of the ocean. Winds and tides hence ultimately need to be considered as the driver of the AMOC. 


\subsection{Energy Budget}

[20] Let us place Sandström's theorem in a broader framework by considering all possible energy sources. The following is based on the work of Gill [1982], Oort et al. [1994], and Wunsch and Ferrari [2004]. The total energy of a fluid parcel is given by its internal, GPE, and kinetic energy. We will now consider the balances of each of these terms separately.

[21] The internal energy (I) balance per unit mass is

$$
\begin{aligned}
\frac{\partial(\rho I)}{\partial t} & +\boldsymbol{\nabla} \cdot\left[\rho I \mathbf{u}+\mathbf{F}_{\mathrm{rad}}\right] \\
& +\boldsymbol{\nabla} \cdot\left[-\rho c_{p} \kappa_{T} \boldsymbol{\nabla} T-\frac{\partial h_{E}}{\partial S} \rho \kappa_{S} \boldsymbol{\nabla} S\right]=-p \boldsymbol{\nabla} \cdot \mathbf{u}+\rho \epsilon,
\end{aligned}
$$

where $\rho$ is the in situ density, $\mathbf{u}$ is the velocity, $T$ and $S$ are the temperature and salinity, respectively, $\mathbf{F}_{\text {rad }}$ represents the radiative flux, $c_{p}$ is the specific heat of seawater at constant pressure, $\kappa_{T}$ and $\kappa_{S}$ are the heat and salt diffusivities, respectively, $h_{E}=I+p / \rho$ is the enthalpy, and $\epsilon$ is the viscous dissipation rate,

$$
\epsilon=\nu\left\{\left(\frac{\partial \mathbf{u}}{\partial x}\right)^{2}+\left(\frac{\partial \mathbf{u}}{\partial y}\right)^{2}+\left(\frac{\partial \mathbf{u}}{\partial z}\right)^{2}\right\},
$$

where $\nu$ is the molecular kinematic viscosity $(\nu=\mu / \rho$, $\mu$ being the molecular dynamic viscosity). Here $\rho c_{p} \kappa_{T} \nabla T$ represents the diffusion of heat, and $\frac{\partial h_{E}}{\partial S} \rho \kappa_{S} \nabla S$ is the generation of internal energy due to different enthalpies of salt and water; $p \boldsymbol{\nabla}$. u represents the work done by expansion at the expense of internal energy, and $\rho \epsilon$ is the heat produced by viscous dissipation of kinetic energy.

[22] The GPE balance for a fluid parcel is

$$
\frac{\partial(\rho \phi)}{\partial t}+\nabla \cdot(\rho \phi \mathbf{u})=\rho \mathbf{u} \cdot \nabla \phi+\rho \frac{\partial \phi_{\text {tides }}}{\partial t},
$$

where $\phi$ is the gravitational potential, which includes both the Earth's geopotential and a time-dependent tidal potential $\left[\phi=g z+\phi_{\text {tides }}(x, y, z, t)\right.$, with the gravitational acceleration $g]$. The term $\rho \mathbf{u} \cdot \boldsymbol{\nabla} \phi$ represents the conversion of kinetic energy to GPE (see below).

[23] Finally, the balance of kinetic energy for a fluid parcel is

$$
\begin{aligned}
\frac{\partial}{\partial t}\left(\frac{1}{2} \rho|\mathbf{u}|^{2}\right)+\nabla \cdot\left(\frac{1}{2} \rho \mathbf{u}|\mathbf{u}|^{2}\right)= & \boldsymbol{\nabla} \cdot\left[\mu \nabla\left(\frac{1}{2} \rho|\mathbf{u}|^{2}\right)\right]-\mathbf{u} \cdot \nabla p \\
& -\rho \mathbf{u} \cdot \boldsymbol{\nabla} \phi-\rho \epsilon .
\end{aligned}
$$

The first term on the right-hand side represents the diffusion of kinetic energy due to viscous processes. The second term represents the work done by pressure forces, which can be written as $-\mathbf{u} \cdot \boldsymbol{\nabla} p=-\boldsymbol{\nabla} \cdot(p \mathbf{u})+p \boldsymbol{\nabla} \cdot \mathbf{u}$, where $p \boldsymbol{\nabla} \cdot \mathbf{u}$ is the compressive term appearing with opposite sign in (5). The third term appears with opposite signs in equations (7) and (8) and represents the work done by gravity and tidal forces (i.e., the GPE to kinetic energy conversion). The fourth term appears with opposite signs in equations (5) and
(8) and represents the dissipation of kinetic energy produced by viscous dissipation (friction). Replacing $\phi=g z+\phi_{\text {tides }}$, we have

$$
\begin{aligned}
\frac{\partial}{\partial t}\left(\frac{1}{2} \rho|\mathbf{u}|^{2}\right)+\nabla \cdot\left(\frac{1}{2} \rho \mathbf{u}|\mathbf{u}|^{2}\right)= & \boldsymbol{\nabla} \cdot\left[\mu \boldsymbol{\nabla}\left(\frac{1}{2} \rho|\mathbf{u}|^{2}\right)\right]-\mathbf{u} \cdot \nabla p \\
& -\rho w g-\rho \mathbf{u} \cdot \boldsymbol{\nabla} \phi_{\text {tides }}-\rho \epsilon
\end{aligned}
$$

where $w$ is upwelling velocity. We now consider the steady state volume integral of (9). In the steady state the first term on the left-hand side vanishes. As explained as well by Wunsch and Ferrari [2004], the second term on the lefthand side represents the advection of kinetic energy through the boundaries. Since advection through the lateral boundaries or the bottom is not possible, this term is reduced to the advection of kinetic energy through the surface. Faller [1968] estimated the kinetic energy input through the surface associated with precipitation at less than $4 \times 10^{-4} \mathrm{PW}$. Although not negligible, most of this energy is expended in small-scale turbulence close to the surface.

[24] Thus, neglecting this term,

$$
\begin{aligned}
& \int_{S} {\left[\mu \boldsymbol{\nabla}\left(\frac{1}{2} \rho|\mathbf{u}|^{2}\right)\right] \cdot \hat{\mathbf{n}} d s } \\
& \quad+\int_{V}\left[-\mathbf{u} \cdot \nabla p-\rho w g-\rho \mathbf{u} \cdot \nabla \phi_{\text {tides }}-\rho \epsilon\right] d v=0,
\end{aligned}
$$

where $\hat{\mathbf{n}}$ is an outward unit vector normal to the boundaries of the ocean at each point and $d v$ is a volume element. This implies that in the steady state the energy input by the winds (the first term on the left-hand side) plus the work done by pressure gradients, the work done by gravity, and the energy input though tidal forcing must balance the dissipation of kinetic energy by friction.

[25] The work done by pressure gradients can be expressed in terms of the net vertical buoyancy flux and the nonhydrostatic pressure work. We decompose the pressure $p$ into its hydrostatic, horizontally averaged component $p_{o}$ and its nonhydrostatic component $p^{\prime}, p=p_{o}+p^{\prime}$. By definition,

$$
\frac{d p_{o}}{d z}=-\rho_{o} g
$$

where $\rho_{o}$ is the horizontally averaged density. Thus

$$
\begin{aligned}
-\mathbf{u} \cdot \nabla p & =-\mathbf{u} \cdot \boldsymbol{\nabla}\left(p_{o}+p^{\prime}\right) \\
& =\rho_{o} w g-\mathbf{u} \cdot \nabla p^{\prime} \\
& =\rho_{o} w b+\rho w g-\mathbf{u} \cdot \nabla p^{\prime},
\end{aligned}
$$

where

$$
b=g \frac{\rho_{o}-\rho}{\rho_{o}}
$$

is the buoyancy. Inserting (12) into (10), the $\rho w g$ term that appears with opposite signs in these expressions cancels 
out. Another way of seeing this is integrating over the ocean volume and taking into account that in a steady state there is no net vertical mass flux across any horizontal surface [e.g., Wunsch and Ferrari, 2004], i.e., $\int_{V} \rho w g d v=0$; we have

$$
\int_{V}-\mathbf{u} \cdot \nabla p d v=\int_{V} \rho_{o} w b d v-\int_{V} \mathbf{u} \cdot \nabla p^{\prime} d v
$$

that is, the pressure work appears as that of the buoyancy forces plus that of the nonhydrostatic pressure [Colin de Verdière, 1993; Wunsch and Ferrari, 2004]. Inserting (12) or (14) into (10) and integrating by parts the second term on the right-hand side of (14), we obtain

$$
\begin{aligned}
\int_{S} & {\left[\mu \boldsymbol{\nabla}\left(\frac{1}{2} \rho|\mathbf{u}|^{2}\right)\right] \cdot \hat{\mathbf{n}} d s } \\
& +\int_{V}\left[-\rho \mathbf{u} \cdot \boldsymbol{\nabla} \phi_{\text {tides }}+p^{\prime} \boldsymbol{\nabla} \cdot \mathbf{u}+\rho_{o} w b-\rho \epsilon\right] d v=0 .
\end{aligned}
$$

This implies that in steady state the energy input by the surface winds, the tides, compression, and buoyancy forces must balance the dissipation of kinetic energy. Taking into account the continuity equation, the compressive term can be written as

$$
\begin{aligned}
p^{\prime} \boldsymbol{\nabla} \cdot \mathbf{u} & =-\frac{p^{\prime}}{\rho} \frac{D \rho}{D t} \\
& =-p^{\prime}\left\{\frac{1}{\rho c_{s}^{2}} \frac{D p}{D t}+\beta \frac{D s}{D t}-\alpha \frac{D \theta}{D t}\right\},
\end{aligned}
$$

where $D / D t$ is the material derivative, $s$ is salinity, $\theta$ is potential temperature, and $\alpha$ and $\beta$ are the corresponding expansion coefficients. Since water is nearly incompressible, the first term on the right-hand side can be safely neglected. In addition, because diffusive fluxes are important only close to the surface because of heat and freshwater fluxes, in the ocean interior the second and third terms on the right-hand side can be neglected. Thus the compressive work term is small, and we neglect it hereinafter. We now analyze the implications of this balance in the case of buoyancy forcing alone.

\subsection{Convective and Nonconvective Systems}

[26] Let us consider now the case in which there is no wind or tidal forcing but only buoyancy forcing, which in the general case can be located anywhere in the ocean. Equation (15) then reads

$$
\int_{V}\left[\rho_{o} w b-\rho \epsilon\right] d v=0
$$

that is, in the absence of any other energy source besides heating or cooling leading to buoyancy forcing, a steady state circulation requires the work done by buoyancy forces to balance the dissipation of kinetic energy through friction. Since the latter implies a sink of kinetic energy, it must be positive. This implies

$$
\int_{V} w b d v>0
$$

that is, the net vertical buoyancy flux must be positive. Thus upwelling must be positively correlated with positive buoyancy, i.e., lighter water, and downwelling must be positively correlated with negative buoyancy, i.e., denser water. Equation (18) expresses the condition required for a system to be a convective system [e.g., Gnanadesikan et al., 2005]. That is, in a convective system, buoyancy forces do net work against friction to maintain the circulation. Thus buoyancy forcing drives the circulation. This is equivalent to the condition for a heat engine (equation (2)).

[27] Let us consider the buoyancy conservation equation

$$
\frac{\partial b}{\partial t}+\nabla \cdot(\mathbf{u} b)=Q_{b},
$$

where $Q_{b}$ is a buoyancy source term. In the steady state and integrating horizontally over $x$ and $y$ and vertically from the bottom of the ocean $(z=-H)$ to some depth level $z_{0}$ below the surface, we have

$$
\left.\langle\overline{w b}\rangle\right|_{-H} ^{z_{o}}=\int_{-H}^{z_{o}}\left\langle\overline{Q_{b}}\right\rangle d z
$$

where the angle brackets indicate horizontally integrated and the overbar indicates steady state quantities.

[28] Hence, in order to have a positive buoyancy flux whatever the value of $z_{o}$ as required from the dissipation in the kinetic energy balance, buoyancy sources must be located at a larger depth than buoyancy sinks.

[29] Paparella and Young [2002] and Gnanadesikan et al. [2005] have shown that when the sole forcing on a fluid is surface buoyancy flux (horizontal convection), the net steady state vertical buoyancy flux across every surface $z=$ constant vanishes, i.e.,

$$
\langle\overline{w b}\rangle \equiv \int_{S} w b d s=0
$$

where the surface integral is calculated at a constant depth. In particular, for the total volume integrated, time-averaged vertical buoyancy flux we have

$$
\int_{V} \overline{w b} d v=0
$$

This is approximately the case of the ocean, where the buoyancy forcing is practically limited to the surface. Thus the net work done by buoyancy forces is zero in a steady state, and buoyancy forcing can in this sense not be considered as the driver of the flow. This is equivalent to Sandström's theorem.

[30] As pointed out by Paparella and Young [2002] and Gnanadesikan et al. [2005], this does not necessarily imply that the flow is zero. To see this, the total vertical velocity and buoyancy are decomposed into their large-scale, longterm and small-scale, short-term components $\bar{w}, \bar{b}$ and $w^{\prime}, b^{\prime}$, respectively, i.e., $w=\bar{w}+w^{\prime}$ and $b=\bar{b}+b^{\prime}$. Thus equation (21) would be

$$
\langle\overline{w b}\rangle=\langle\bar{w} \bar{b}\rangle+\left\langle\overline{w^{\prime} b^{\prime}}\right\rangle=0
$$


if $\left\langle\overline{w^{\prime} b^{\prime}}\right\rangle \neq 0$, this implies that there must be a compensation of the work done by buoyancy forces on the large-scale, long-term and the small-scale, short-term components. Thus, even if for the total flow the net vertical buoyancy flux vanishes, for the large-scale flow it does not. The corresponding pertinent kinetic energy balance would be the large-scale version of (17), i.e.,

$$
\int_{V}[\bar{w} \bar{b}-\epsilon] d v=0,
$$

where the Boussinesq approximation has been taken into account. Note that here

$$
\epsilon=A\left\{\left(\frac{\partial \overline{\mathbf{u}}}{\partial x}\right)^{2}+\left(\frac{\partial \overline{\mathbf{u}}}{\partial y}\right)^{2}+\left(\frac{\partial \overline{\mathbf{u}}}{\partial z}\right)^{2}\right\}
$$

is the turbulent viscous dissipation rate of large-scale kinetic energy, and $A$ includes the eddy and molecular kinematic viscosities.

[31] Thus (23) represents a balance between two equal and opposite terms, the first of which compensates the large-scale kinetic energy dissipation.

[32] If the term $\left\langle\overline{w^{\prime} b^{\prime}}\right\rangle$ is parameterized as vertical diffusion with a vertical diffusivity coefficient $\kappa$, we have

$$
\langle\bar{w} \bar{b}\rangle-\kappa\left\langle\bar{b}_{z}\right\rangle=0 .
$$

As shown by Paparella and Young [2002], integrating (26) over the ocean depth, the following is obtained for the total large-scale buoyancy flux in the steady state:

$$
\begin{aligned}
\int_{V} \bar{w} \bar{b} d v & =\int_{-H}^{0}\langle\bar{w} \bar{b}\rangle d z \\
& =\kappa[\langle\bar{b}(0)\rangle-\langle\bar{b}(-H)\rangle] \\
& =\int_{V} \epsilon d v
\end{aligned}
$$

where $\langle\bar{b}(0)\rangle$ and $\langle\bar{b}(-H)\rangle$ are the horizontally integrated large-scale, long-term buoyancies on the surface and at depth, respectively. In the limit $\kappa \rightarrow 0$ the dissipation $\epsilon \rightarrow 0$, instead of reaching a finite limit independent of viscosity, as is the case for a turbulent fluid. In other words, a horizontal convective system cannot exhibit the observed small-scale turbulence observed in the ocean. Hence the whole flow must also be zero.

[33] However, horizontal convection is able to drive a flow in which no energy is dissipated by turbulent mixing. This is seen in experiments [Stommel, 1962; Rossby, 1965] and numerical studies [Beardsley and Festa, 1972; Rossby, 1998]. In these cases the heat is transported from the boundary into the fluid by molecular diffusion and conduction. Coman et al. [2006] repeated Sandström's [1908, 1916] experiments in the original setup. They observed an overturning circulation and conclude that Sandström failed to detect this. Sandström [1908, 1916] was not aware of diffusion, as Jeffreys [1925] pointed out. Yet, as already noted [Bjerknes, 1916], the idea behind Sandström's theorem is still valid: The heat fluxes through the ocean surface must continue into the ocean itself, penetrating it, in order to set up a deep circulation. The heat flux penetrating the fluid can be caused by molecular or turbulent mixing.

[34] Is molecular diffusion sufficient to drive a flow as vigorous as observed in the ocean? Siggers et al. [2004] show a theoretical possibility for the observed horizontal heat transport to be achieved in this way. Mullarney et al. [2004], in a tank experiment, even see a horizontal convective flow with an eddying surface layer similar to the observed one. The occurrence of a flow of this kind depends on the parameters of the experiment, like length scales and applied temperature differences. However, an estimate of the energy from surface thermal forcing available to the ocean yields an amount at least 10,000 times smaller than the mechanical energy from wind and tidal dissipation [Wang and Huang, 2005] (see Table 1). Therefore it appears that turbulent mixing driven by winds and tides is necessary to sustain the upwelling of deep water across the stratification, as it is observed in the ocean. This implies that surface buoyancy fluxes do not drive the MOC but are rather a passive result of the latter [Munk and Wunsch, 1998; Huang, 2004]. Once an external energy source, capable of sustaining turbulence, is introduced, a MOC can be driven.

[35] Turbulent mixing as a driver of the global MOC, along with the required sources of external energy, is discussed in section 3. Another possible driver is the direct input of large-scale kinetic energy through the winds. This driver does not involve diapycnal mixing but rather winddriven, isopycnal upwelling (see section 4).

\section{DIAPYCNAL MIXING AS A DRIVER FOR THE OVERTURNING CIRCULATION}

[36] In this section we discuss the hypothesis that diapycnal mixing is the main driver of the AMOC by contributing most of the potential energy needed for the deepwater masses formed in the North Atlantic to return back to the surface. The most important process that gives rise to mixing is the breaking of internal waves [Garrett and St. Laurent, 2002; St. Laurent and Garrett, 2002; Wunsch and Ferrari, 2004] generated by (1) the wind at the surface, (2) the interaction of abyssal tidal flow with topography, and (3) the interaction of the eddy field with bottom topography.

[37] The term "diapycnal" refers to turbulent mixing across surfaces of equal density, as compared to "isopycnal" mixing, which occurs along those surfaces. The zonally averaged density profile in Figure 2 shows that vertical mixing is diapycnal in most parts of the ocean. There are, however, exceptions where vertical mixing has a strong isopycnal component because of sloping isopycnals. This happens in the high latitudes, where the isopycnals outcrop at the surface, in frontal regions such as the Antarctic Circumpolar Current, and in western boundary currents. Mixing along isopycnal surfaces is much more pronounced since it occurs with the least expenditure of energy. Hence, although essential as a potential driver of the 
MOC, the diapycnal mixing coefficient is typically several orders of magnitude smaller than the isopycnal one. Note that by mixing we mean small-scale turbulent motions in the ocean that occur on centimeter scales up to mesoscale eddies, whose spatial scales are on the order of $1-50 \mathrm{~km}$.

\subsection{Mixing Coefficients}

[38] Because of the lack of data, and to simplify matters, the diapycnal mixing coefficient was initially assumed to be uniform throughout the ocean interior, implying a uniformly distributed, slow upwelling over large regions of the oceans [Stommel and Arons, 1960]. Assuming that vertical advection $w$ and turbulent mixing are the dominant terms in the transport equation of a conservative tracer $C$ leads to a vertical advection-diffusion balance

$$
w \partial_{z} C=\partial_{z}\left(\kappa \partial_{z} C\right),
$$

with a vertical turbulent diffusion coefficient $\kappa$. Here turbulent mixing has been parameterized as turbulent diffusion, analogous to molecular diffusion. Munk [1966] assumed a constant $\kappa$ and estimated a value of $\kappa=1 \times$ $10^{-4} \mathrm{~m}^{2} \mathrm{~s}^{-1}$ for the diapycnal turbulent diffusivity by fitting this balance pointwise to tracer data from the central Pacific Ocean. Since then, $\kappa=1 \times 10^{-4} \mathrm{~m}^{2} \mathrm{~s}^{-1}$ was widely regarded as the proper diapycnal mixing coefficient needed to return the deep waters back to the surface.

[39] However, in recent years, direct and indirect measurements of mixing coefficients have revealed that diapycnal mixing is highly variable in space. Interior mixing rates away from topographic features and boundaries indicate values of the order of only $\kappa=0.1 \times 10^{-4} \mathrm{~m}^{2} \mathrm{~s}^{-1}$ [Moum and Osborn, 1986; Ledwell et al., 1993; Oakey et al., 1994] and even lower values close to the equator [Gregg et al., 2003]. Strong mixing with turbulent diffusion coefficients up to $\kappa=100 \times 10^{-4} \mathrm{~m}^{2} \mathrm{~s}^{-1}$, on the other hand, can be found near highly variable bottom topography [Polzin et al., 1997; Ledwell et al., 2000; Garabato et al., 2004b] or along continental slopes [Moum et al., 2002].

[40] Taking into account that mixing is highly variable in space, Munk and Wunsch [1998] reestimated the basin average diapycnal turbulent diffusivity by applying the vertical advection-diffusion balance to zonally averaged densities. They interpreted the resulting turbulent diffusivity as a surrogate for a small number of concentrated mixing regions from which the mixed water masses are exported to the ocean interior. Their analysis was based on the assumption that all of the estimated $30 \mathrm{~Sv}$ of deep water that is formed at both northern and southern high latitudes (see section 5) upwells at low latitudes between depths of $1000 \mathrm{~m}$ and $4000 \mathrm{~m}$. This approach resulted in the same globally averaged value of $\kappa=1 \times 10^{-4} \mathrm{~m}^{2} \mathrm{~s}^{-1}$. Munk and Wunsch [1998] hypothesized that the power required to mix waters with a uniform coefficient of $\kappa=1 \times 10^{-4} \mathrm{~m}^{2} \mathrm{~s}^{-1}$ is the same as if concentrated mixing occurred with much higher coefficients in only about $1 \%$ of the ocean, thus reaffirming $\kappa=1 \times 10^{-4} \mathrm{~m}^{2} \mathrm{~s}^{-1}$ as the average diapycnal mixing coefficient required to return the deep waters back to the surface.

\subsection{Mixing Energy Requirements}

[41] We reconsider here the energy balance for a nonconvective system like the ocean (equation (23)) in which the net buoyancy transport is zero,

$$
\langle\overline{w b}\rangle=\langle\bar{w} \bar{b}\rangle+\left\langle\overline{w^{\prime} b^{\prime}}\right\rangle=0,
$$

where the overbar again denotes large-scale long-term averages. We assume the mechanical energy source for sustaining the flow is from diapycnal mixing, supplied through $\overline{w^{\prime} b^{\prime}}$. We remind the reader that the angle brackets denote the horizontal integral, so equation (29) holds for every depth level below the surface. The direct wind input into the large-scale kinetic energy balance is neglected here, and from the volume-integrated kinetic energy balance (equation (17)):

$$
\int_{V} \rho_{0} \bar{w} \bar{b} d v=-\int_{V} \rho_{0} \overline{w^{\prime} b^{\prime}} d v=\int_{V} \rho \epsilon d v
$$

the energy required to sustain the flow can be estimated. Since the dissipation term on the right-hand side is positive, the large-scale potential to kinetic energy conversion term $\bar{w} \bar{b}$ is positive, and potential energy supplied by diapycnal mixing is converted into large-scale kinetic energy and drives the flow.

[42] Munk and Wunsch [1998] used the closure from equation (28) for the turbulent mixing term in equation (30) $\rho_{0} \overline{w^{\prime} b^{\prime}} \equiv \rho_{0} \kappa(z) \partial_{z} b\left(\mathrm{~W} \mathrm{~m}^{-3}\right)$ and estimated the amount of energy production $E_{\text {mix }}(z)$ required to maintain the abyssal stratification against an upwelling velocity $w(z)$ :

$$
E_{\text {mix }}(z)=\kappa(z) \rho_{0} \partial_{z} b=-\kappa(z) g \partial_{z} \rho(z),
$$

where $\kappa$ is the depth-dependent turbulent diffusivity as computed from the density distribution and the assumed upwelling of $30 \mathrm{~Sv}$ in the low-latitude oceans and $\rho$ is the density. By integrating equation (31) over the global abyssal ocean volume, they obtained that a total of $0.4 \mathrm{TW}$ of energy input is required.

[43] Alternatively, Wunsch and Ferrari [2004] also estimated the energy requirement from the term on the left-hand side of equation (30), by considering the density difference between the denser downwelling and less dense upwelling waters. Again, inserting vertical velocities consistent with a total of about $30 \mathrm{~Sv}$ volume transport that needs to upwell across stratification and density profiles consistent with observations, one obtains the same result of $0.4 \mathrm{TW}$.

[44] The question remains whether the required energy production is available in reality. This depends crucially on how and where the turbulent kinetic energy provided by the winds and tides is made available for mixing. This energy is supplied at large scales (up to $1000 \mathrm{~km}$ ) and then transferred across the internal wave spectrum to small dissipation scales (centimeters to millimeters); however, dissipation mechanisms are poorly known and quantified [Kantha and Clayson, 2000]. In the ocean interior the energy distribution of the internal wavefields is well described by 
the Garrett-Munk wave number/frequency spectrum [Garrett and Munk, 1972, 1975; Munk, 1981]. Generally, the energy content of the Garrett-Munk spectrum seems to be able to explain the measured values of diapycnal diffusivity in the order of $0.1 \times 10^{-4} \mathrm{~m}^{2} \mathrm{~s}^{-1}$ in the ocean interior [Kantha and Clayson, 2000]. The interaction of abyssal tidal flow with bottom topography is probably responsible for most of the localized elevated mixing rates near the bottom of the ocean. How much of the tidal energy is locally dissipated near their generation site or radiated away is, however, still unclear [St. Laurent and Garrett, 2002; Garrett and St. Laurent, 2002].

[45] Therefore estimates of the amount of energy available for mixing in the real ocean rely on estimates of energy production rates and energy pathways and are highly uncertain. Faller [1968] and Holland [1975] were the first to estimate the terms of the energy budget of the general circulation. The following discussion of these estimates is summarized in Table 1. The total amount of mechanical energy input by the winds can be partitioned as in the work of Wang and Huang [2004a] into

$$
W_{\text {wind }}=\boldsymbol{\tau} \cdot \mathbf{u}_{\mathbf{o}}+\overline{\boldsymbol{\tau}^{\prime} \cdot \mathbf{u}_{\mathbf{o}}^{\prime}}+\overline{p^{\prime} w_{o}^{\prime}},
$$

where $\tau$ and $\mathbf{u}_{\mathbf{o}}$ are the long-term large-scale surface wind stress and velocity, respectively, $\boldsymbol{\tau}^{\prime}$ and $\mathbf{u}_{\mathbf{o}}^{\prime}$ are the respective high-frequency perturbations associated with surface waves, and $p^{\prime}$ and $w_{o}^{\prime}$ are perturbations of the surface pressure and vertical velocity, respectively. In equation (32) we have dropped, for simplicity, the overbar in all quantities that refer to large-scale long-term averages. Splitting the horizontal surface velocity into its geostrophic and ageostrophic components, we have

$$
W_{\text {wind }}=\boldsymbol{\tau} \cdot \mathbf{u}_{\mathbf{o}, \mathbf{g}}+\boldsymbol{\tau} \cdot \mathbf{u}_{\mathbf{0}, \mathbf{a}}+\overline{\boldsymbol{\tau}^{\prime} \cdot \mathbf{u}_{\mathbf{0}}^{\prime}}+\overline{p^{\prime} w_{o}^{\prime}} .
$$

[46] The first term represents the work done by the surface winds on the geostrophic flow, estimated by Wunsch [1998] to be 1 TW. Most of this large-scale energy enters through the Southern Ocean and is the subject of section 4 . Here we are interested in how much is eventually available for mixing, and Wunsch and Ferrari [2004] argue that this potential energy is mainly lost through baroclinic instability resulting in mixing. The second wind input term is the work on the ageostrophic flow, estimated to be about 3 TW [Wang and Huang, 2004a; Watanabe and Hibiya, 2002; Alford, 2003]. The third and fourth terms are the work of the wind stress on surface waves. They represent by far the largest contribution, estimated by Wang and Huang [2004b] to be $60 \mathrm{TW}$, most of which is shown to enter the ocean through the Antarctic Circumpolar Current. However, as pointed out by Wang and Huang [2004b], this does not mean that the latter term is the dominant energy input to the large-scale oceanic energy balance, since a large fraction is bound to be dissipated in the surface layer. All of the wind energy input terms also contribute indirectly to mixing through generation of internal waves, which probably constitute the bulk of background mixing. In total, a rough estimate is that about $1 \mathrm{TW}$ of wind energy input is available for turbulent mixing.

[47] The energy input by tides in the ocean is estimated to be about $3.5 \mathrm{TW}$, most of which is thought to be dissipated on the continental shelves, but around 1 TW would be available for abyssal mixing through the generation of internal waves and turbulence [Munk and Wunsch, 1998; Egbert and Ray, 2000]. It needs to be stressed that energy pathways are not known well enough and the above represents a very brief summary of the current understanding of the mechanical energy balance of the ocean that is discussed in more detail by Wunsch and Ferrari [2004]. Overall, a crude estimate is that winds and tides provide mixing energy with a rate of about $2 \mathrm{TW}$.

[48] The largest part of this mixing energy is directly dissipated through viscous friction. Only a fraction of this turbulent kinetic energy production, determined by the mixing efficiency $\gamma$, is converted to potential energy and hence mixing. Osborn [1980] estimated the mixing efficiency to be $\gamma=0.2$, pointing out that this value may depend strongly on the mechanism causing the turbulence. This value results in a very rough estimate of $0.4 \mathrm{TW}$ directly available for diapycnal mixing from winds and tides.

[49] The above discussion implies that if the ocean's deep overturning circulation is to be driven mainly by mixing, the amount of energy required for mixing, as estimated by Munk and Wunsch [1998] (see equation (31)), is just about that which is available. However, such estimates and this conclusion rely on assumptions that need to be critically assessed. Munk and Wunsch's [1998] numbers for the energies and diffusivities are based on the assumption that all estimated $30 \mathrm{~Sv}$ of the globally formed deep water (see section 5) upwell in low latitudes across stratification. All $0.4 \mathrm{TW}$ of tidal and wind energy would need to be converted to a kind of mixing that allows deep waters to rise up to the surface. This implies that the energy supply has to act where stratification is high and not in an already mixed water column. Evaluating the driving forces for the AMOC requires assessing how much NADW actually upwells across stratification or, alternatively, at a density similar to that at which it was formed (see section 4).

[50] A further underlying assumption in the estimates of Munk and Wunsch [1998] is that although mixing is locally enhanced at the ocean boundaries, there exists a horizontal homogenization of water masses, meaning the mixed water masses have to be exported to the ocean interior [see, e.g., Garrett et al., 1993]. This horizontal homogenization is a prerequisite to applying the vertical advection-diffusion balance to zonally averaged quantities [Caldwell and Moum, 1995]. The question of whether boundary mixing is vigorous enough and can work such that it explains basinaveraged diffusivities remains unresolved.

[51] Gade and Gustafsson [2004] have analyzed the oceanic circulation's energy requirements as well as the implied mass transport by assuming the ocean circulation operates in closed cycles in pressure-volume diagrams. 
These, they show, can be estimated from the density distribution, considering geothermal heating and diapycnal mixing. Four types of circulation patterns emerge, with different deepwater formation in the North Atlantic. The implied energy requirements depend on the details of the circulation pattern. With the estimate of 2 TW available [Munk and Wunsch, 1998], Gade and Gustafsson [2004] estimate a very weak implied flow of about $3 \mathrm{~Sv}$. However, as Gade and Gustafsson [2004] recognize, the circulation patterns considered were relatively simplified, and more realistic flow patterns with more than one deepwater formation source should be considered.

[52] There is an effect that considerably reduces the required amount of mixing. Hughes and Griffiths [2006] studied the effect of entrainment in a conceptual model. Dense waters formed at the surface flow down the continental slopes. On their way down they entrain the surrounding waters with them. Consequently, these entrained waters need not upwell to the surface but only to intermediate depths, and the amount of mixing to sustain an AMOC is much less than the 2 TW estimated by Munk and Wunsch [1998].

[53] Another issue is the highly uncertain value for the mixing efficiency $\gamma=0.2$. Studies from the main thermocline indicate a much lower value of $\gamma=0.05$ [Caldwell and Moum, 1995]. Recent estimates from a large observational database give $\gamma=0.12$ [Arneborg, 2002], which would imply that an energy input of about $3.5 \mathrm{TW}$, instead of the 2 TW estimated above, is required to balance the upwelling. Peltier and Caulfield [2003] recently point out that the mixing efficiency varies widely depending on the fluid environment. Given this large uncertainty, it seems that with today's knowledge we cannot reliably determine the turbulent mixing energy budget.

\subsection{Diapycnal Mixing in Ocean Models}

[54] Model studies are helpful to gain insight into how the spatial distribution of vertical mixing in the ocean influences the AMOC. Most ocean models show that the deep overturning circulation and heat transport are very sensitive to the employed diapycnal diffusivity coefficient [Bryan, 1987; Zhang et al., 1999; Mignot et al., 2006]. Given the lack of theories on how to parameterize smallscale scale mixing in terms of large-scale quantities, mixing coefficients in ocean models are often used as tuning parameters to achieve the most realistic simulation regarding large-scale observable quantities (surface currents, tracer concentrations and transports, etc.). However, it has to be kept in mind that the employed mixing might partly correct for model deficiencies, many of which arise from the coarse horizontal and vertical resolution (e.g., representation of western boundary currents and deepwater formation processes). Moreover, mixing is not allowed to evolve with the ocean circulation in a changing climate.

[55] Commonly, uniform mixing coefficients or an arctangent vertical profile with interior mixing values of $0.3 \times$ $10^{-4} \mathrm{~m}^{2} \mathrm{~s}^{-1}$ increasing to $1.3 \times 10^{-4} \mathrm{~m}^{2} \mathrm{~s}^{-1}$ at the ocean bottom [Bryan and Lewis, 1979] is employed. Attempts to express mixing coefficients in terms of model parameters include vertical diffusivity dependent on stratification [Cummins et al., 1990] or related to the Richardson number [Large et al., 1994].

[56] The influence of mixing location on meridional overturning in ocean models was examined by Marotzke [1997], who imposed mixing only at the boundaries, and by Scott and Marotzke [2002], who concentrated mixing entirely at high or low latitudes in or below the thermocline or at the boundaries. Both studies concluded that boundary mixing is more efficient in driving a MOC than mixing in the interior. They relate the meridional density difference in their one-hemisphere model to the east-west density difference in the western boundary current that determines the volume transport and conclude that interior upwelling hinders the processes leading to these east-west density differences. Scott and Marotzke [2002] found that mixing at depths below the thermocline until close to the bottom is not required to generate a deep flow and has little effect on the strength of the circulation through the thermocline. Both studies employ a one-hemisphere model without wind forcing and without bottom topography, which poses a limitation to the validity of the results for more realistic global ocean models.

[57] The effects of topographically enhanced mixing were investigated by Hasumi and Suginohara [1999]. In a global ocean model with realistic topography and wind forcing they increased the diffusivity where subgrid-scale bottom roughness exceeded a certain threshold. Their simulations show that upwelling and circulation of the bottom to deepwater masses is affected by localized deep mixing but that the maximum of the AMOC is insensitive to these changes. In fact, a vigorous AMOC can exist even with a very low background mixing coefficient of only $0.1 \times 10^{-4} \mathrm{~m}^{2} \mathrm{~s}^{-1}$ [Montoya et al., 2005; Saenko and Merryfield, 2005; Mignot et al., 2006; Hofmann and Morales-Maqueda, 2006].

[58] Modeling studies which employ fixed mixing coefficients disregard the amount of mechanical energy required for the mixing. Huang [1999] considered fixed energy profiles from which diffusivities are calculated in an idealized ocean basin with only thermal forcing. He observes a different sensitivity of meridional mass and heat transport to the meridional temperature difference with prescribed energies or prescribed mixing coefficients. However, his parameterization is not conservative: A heat source is introduced where stratification vanishes, which makes it difficult to interpret the results. In his temperature balance equation the diapycnal mixing term appears as $\partial_{t} T_{\text {mixing }}=\partial_{z}[e(z) / g \alpha]$, with $e(z)$ being the fixed external energy source profile for mixing. If stratification goes to zero, so should $e$.

[59] Similarly, Nilsson and Walin [2001], Nilsson et al. [2003], and Mohammad and Nilsson [2004] analyze the behavior of the AMOC that follows from a diffusivity parameterization $\kappa_{v} \propto N^{-q}$, representing the dependence of diffusivity on the local buoyancy frequency $N=$ $\sqrt{-g\left(\partial_{z} \rho / \rho_{0}\right)}$. They conclude that the AMOC may 
intensify rather than decrease with increased freshwater forcing in the North Atlantic. The main deficiency of these simulations is the fact that they were performed with a one-hemisphere model such that the entire overturning circulation had to be driven by mixing (see also section 6.3).

[60] Simmons et al. [2004] used output from a global barotropic tidal model to constrain vertical mixing in an ocean general circulation model (OGCM), representing that part of tidal energy that leads to local topographically enhanced mixing. They added a constant weak background diffusivity of $0.1 \times 10^{-4} \mathrm{~m}^{2} \mathrm{~s}^{-1}$ to the predicted diffusivities in order to account for other nonlocal sources of mixing. This bottom-enhanced mixing improved the representation of deepwater mass properties. The strength of the AMOC was reduced by $50 \%$ compared to a simulation with uniform mixing with a coefficient equal to the average of the nonuniform one. Their decrease in AMOC maximum can be attributed to the low value of $\kappa=0.1 \times 10^{-4} \mathrm{~m}^{2} \mathrm{~s}^{-1}$ at thermocline depth compared to $0.9 \times 10^{-4} \mathrm{~m}^{2} \mathrm{~s}^{-1}$ for the uniform mixing case. Montoya et al. [2005] found a realistically represented $\mathrm{AMOC}$ in a climate model of intermediate complexity that contains an OGCM, using the same low background diffusivity and topographically enhanced mixing (see Figure 3). Saenko and Merryfield [2005] used the same parameterization for vertical diffusivity and specifically addressed the role of the topographically enhanced mixing as compared to a simulation with only a background mixing of $0.1 \times 10^{-4} \mathrm{~m}^{2} \mathrm{~s}^{-1}$. Their simulations reveal a stagnant abyssal North Pacific Ocean in the latter case, whereas the deep stratification and circulation were more realistic with bottom-enhanced mixing even though the inflow of abyssal waters into the Pacific was still far below observational estimates. Interestingly, the AMOC was already realistically modeled in the low background mixing case. These studies indicate that it is important to use nonuniform diffusion coefficients based on energy considerations instead of fixed constant diffusivities in order to represent the driving mechanisms of the AMOC in a more realistic way and consistent with the available energy.

[61] Although in the past decades, spurious diapycnal mixing, that may arise in numerical models [e.g., Veronis, 1975] has been reduced through the incorporation of isopycnal mixing schemes [Redi, 1982; Gent and McWilliams, 1990], possibly the majority of the current ocean models still overestimate the contribution of diapycnal mixing as a driver of the AMOC. Models mostly employ coefficients in the interior ocean much larger than the observed $0.1 \times 10^{-4} \mathrm{~m}^{2} \mathrm{~s}^{-1}$, resulting in deficient heat transport because the temperature contrast between cold southward and warm northward flows is too weak. The coefficient is sometimes increased to obtain a more realistic present-day model AMOC. Yet a model with an overturning circulation that is too weak is not necessarily caused by diapycnal mixing that is too weak; it can be the result of erroneous surface fluxes, insufficient representation of deepwater formation processes, etc.
[62] Ocean models make use of computational tracer advection schemes with implicit numerical diffusion. This additional diffusion is rarely considered. Yet it can be of the same order as the explicitly applied diffusivity [Gerdes et al., 1991; Griffies et al., 2000; Hofmann and MoralesMaqueda, 2006], and it limits the ability to test the model's behavior in the limit of very low diapycnal mixing [Toggweiler and Samuels, 1998].

[63] A further potentially important mechanism for mixing is double diffusion. On the molecular level the diffusivities of heat and salt differ by an order of magnitude, driving convective motions even in a stable stratification. There is evidence that these processes play a significant role in turbulent mixing [Schmitt, 1994], which led a number of authors to apply different ratios of vertical turbulent diffusivities in ocean models [Zhang et al., 1999, and references therein]. The overall implications for the largescale ocean circulation are still unclear; however, double diffusion generally leads to a reduction of the AMOC because of the implied upgradient flux of buoyancy.

[64] How important is mixing for the abyssal stratification of the water masses? Vallis [1999] points out that the source of stratification below the thermocline is not the downward diffusion of heat together with upward advection but, rather, the presence of different water masses in the abyss. In a model without a circumpolar channel and starting from an ocean with uniform density, low values of the vertical diffusivity resulted in a deep ocean with very weak stratification. As soon as an Antarctic circumpolar channel, partially blocked by meridional topography, was added, the deep waters formed there spread equatorward and produced stratification. It is the basin-scale advection that plays the dominant role in setting up the stratification. In fact, the structure and depth of the main thermocline can also be quite well explained with ideal fluid thermocline theory, without directly invoking vertical mixing [Luyten et al., 1983; Jenkins, 1980; Radko and Marshall, 2004].

[65] The study by Vallis [1999] highlights the importance of the model geometry when investigating the role of mixing. Many of the studies mentioned above employed one-hemisphere models with North Atlantic Deep Water formation and without an Antarctic circumpolar channel, with all upwelling necessarily taking place within the Atlantic ocean. As will be discussed in section 4, the winddriven Antarctic Circumpolar Current (ACC) is another, dynamically rather different, potential driver of the AMOC. In a one-hemisphere model without wind forcing the only driving mechanism is diapycnal diffusion, and hence the sensitivity of the AMOC might be inadequately represented. From our current understanding the low observed interior mixing coefficients are consistent with the fact that no significant upwelling of deepwater masses up to the surface has been observed so far at low latitudes (see section 4). Furthermore, another observational constraint is derived from the Sverdrup balance:

$$
\partial_{z} w=\frac{\beta}{f} v,
$$


where $w$ and $v$ are vertical and meridional velocities, respectively, $f$ is the Coriolis parameter, and $\beta=\partial_{y} f$ is its meridional derivative. The Sverdrup balance implies that vertical divergence of vertical motion (left-hand side) will be associated with a meridional velocity (right-hand side). It also means that there can be no meridional flow in the ocean interior in the absence of a vertical velocity $w$, which must cross the horizontal isopycnals. However, apart from western boundary currents a number of observations indicate predominantly zonal flows, which are consistent with locally enhanced mixing at depth [Hogg et al., 1996; Hogg and Owens, 1999; Webb and Suginohara, 2001b] but not with strong interior mixing.

[66] In summary, neither the observations of mixing and upwelling nor the incorporation of mixing into models has been adequately understood to date. The estimates of the individual terms in the energy budget are fraught with large uncertainties. For these reasons it is still difficult to quantify to what extent diapycnal mixing drives the AMOC.

\section{WIND-DRIVEN UPWELLING IN THE SOUTHERN OCEAN}

[67] The alternative hypothesis to upwelling of deepwater masses driven by diapycnal mixing is wind-driven deep upwelling in the Southern Ocean. If this mechanism dominates, the strength of the AMOC is controlled by winds acting on the surface of the Southern Ocean. We now discuss this alternative view and its implications in terms of the energy requirements to drive the MOC.

\subsection{Where Does Deep Upwelling Take Place?}

[68] Several lines of evidence question that deep upwelling occurs in a broad, diffuse manner [Döös and Coward, 1997; Webb and Suginohara, 2001b; Toggweiler and Samuels, 1993b]. Rather, there is evidence for substantial upwelling of deepwater masses occurring in the Southern Ocean. These findings basically stem from the distribution of prebomb radiocarbon [Toggweiler and Samuels, 1993b], rates of biogenic silica production [Gnanadesikan and Toggweiler, 1999], and transect studies of other tracers [Wunsch et al., 1983; Robbins and Toole, 1997].

[69] Prebomb radiocarbon data in the tropical Pacific Ocean reveal an asymmetric distribution of the surface $\Delta^{14} \mathrm{C}$ with respect to the equator [Toggweiler and Samuels, 1993b], indicating that surface water masses in the Northern Hemisphere must be younger than those in the Southern Hemisphere. Toggweiler and Samuels [1993b] conclude that in the case of a strong abyssal upwelling along the equatorial Pacific the $\Delta^{14} \mathrm{C}$ age distribution of sea surface water masses would be symmetric.

[70] Although the relatively high biogenic silica export flux occurring in the eastern equatorial Pacific (7-10 Tmol $\mathrm{yr}^{-1}$ [Gnanadesikan and Toggweiler, 1999]) could indicate a strong upwelling of nutrient-rich water masses in that region, Toggweiler et al. [1991] argue that these water masses need not necessarily originate from an abyssal source, since lower layers of the equatorial undercurrent could feed the eastern equatorial Pacific upwelling system.

[71] The few available high-resolution simulations indicate substantial upwelling of deepwater masses in the Southern Ocean south of the ACC in the latitude band of Drake Passage [Döös and Coward, 1997] (see Figure 5). Observational evidence supporting this conclusion comes again from prebomb radiocarbon data. Newly formed NADW in the Nordic and Labrador seas has ${ }^{14} \mathrm{C}$ values of about -70\% [Broecker and Peng, 1982]. On its way toward the south, $\Delta^{14} \mathrm{C}$ decreases continuously because of radioactive decay of ${ }^{14} \mathrm{C}$ atoms and reaches values of about $-160 \%$ when it enters the ACC (see Figure 6 for details). Sparse prebomb $\Delta^{14} \mathrm{C}$ samples from the sea surface in the Weddell and Ross seas reveal similarly low values of about $-150 \%$ [Toggweiler and Samuels, 1993b], indicating a strong upwelling of deepwater masses.

\subsection{Drake Passage Effect}

[72] In contrast to the rest of the ocean, where winddriven upwelling is confined to the upper ocean, surface winds in the Southern Ocean apparently drive upwelling of deep water [Rintoul et al., 2001; Gnanadesikan and Hallberg, 2002]. What is special about this region of the globe?

[73] The latitude band of Drake Passage, between South America and Antarctica, exhibits topographic characteristics unique on Earth. Except for the Arctic Ocean it is the only oceanic band that circles the Earth without encountering meridional topographic barriers down to a depth of about $2500 \mathrm{~m}$. Below this depth the shallowest topographic features found are the Kerguelen Plateau, in the Indian Ocean part of the Southern Ocean, and the Scotia Arc in the vicinity of the Drake Passage. The profile of this "Drake passage band" is marked as a dashed line in Figure 2. This feature results in a particular dynamic constraint, the so-called Drake Passage effect [Toggweiler and Samuels, 1995]: Because of the lack of meridional topographic barriers the zonally averaged zonal pressure gradient must be zero in this latitude band down to the depths of the shallowest sills. Hence no net meridional geostrophic flow can be sustained at these latitudes and depths, and the zonally integrated geostrophic velocity has to vanish, i.e.,

$$
\oint f v_{g} d x=\frac{1}{\rho} \oint p_{x} d x=0
$$

where the line integral represents any closed contour within the latitudes of the Drake Passage (about $56^{\circ}-63^{\circ} \mathrm{S}$ ) and between the ocean's surface and the shallowest point at each latitude. Thus only ageostrophic meridional flows can be sustained. Such flows may be directly forced by the wind. Surface winds over the Southern Ocean are mainly westerly, driving a northward Ekman transport in the ocean's surface layers of about $30 \mathrm{~Sv}$. The maximum zonal westerly wind stress occurs roughly at $50^{\circ} \mathrm{S}$. Hence south of this area surface divergence leads to upwelling (the Ekman velocity being $\boldsymbol{w}_{\boldsymbol{E}}=\left(\boldsymbol{\nabla} \times \frac{\tau}{f}\right) / \rho_{0}>0$, with the wind stress $\left.\boldsymbol{\tau}\right)$, while north of it there is surface convergence. 


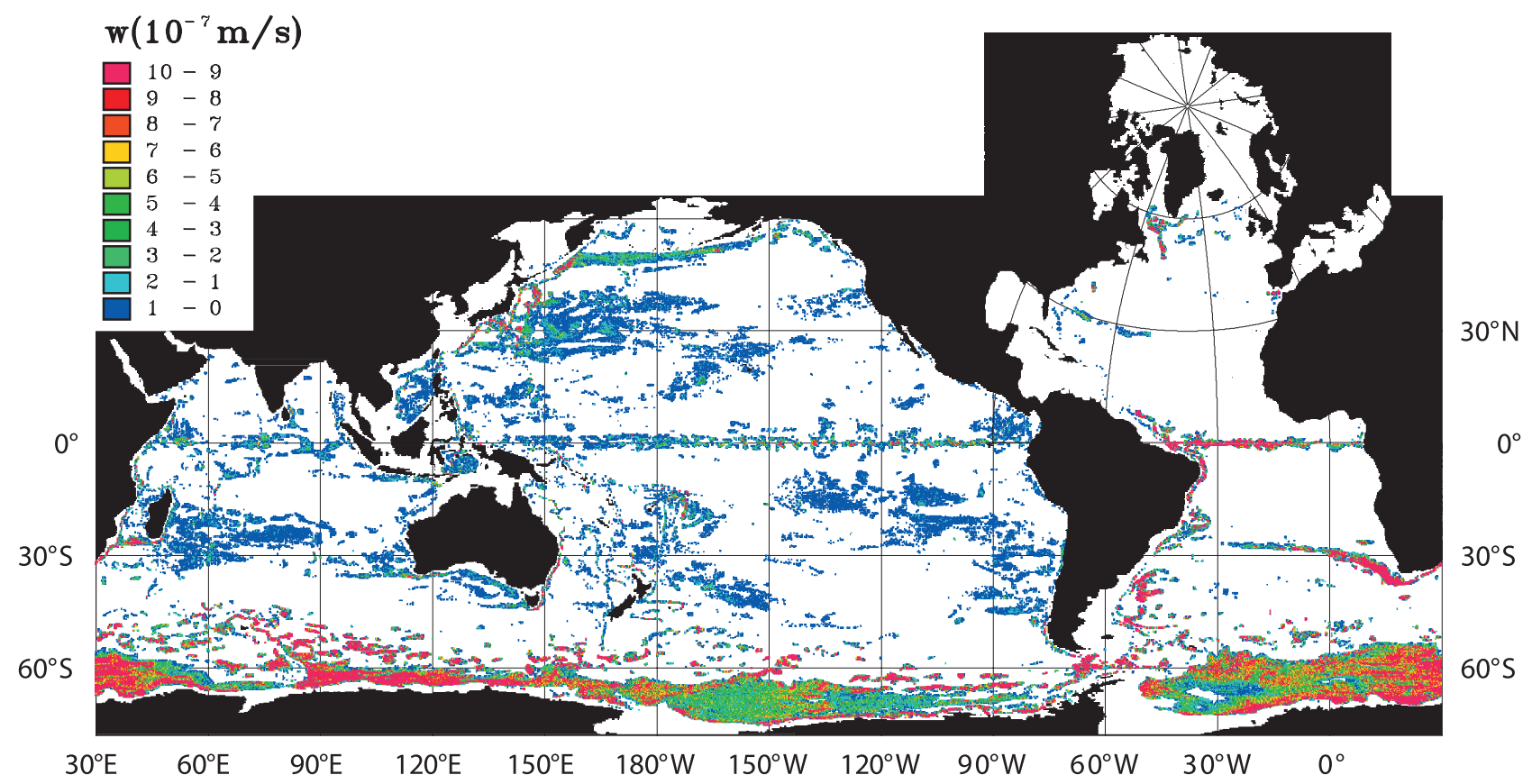

Figure 5. Upwelling regions of NADW in a high-resolution ocean model. The color scale indicates the vertical velocity of NADW as it reaches the isopycnal $1027.625 \mathrm{~kg} \mathrm{~m}^{-3}$, calculated from 1.58 million trajectories. About $60 \%$ of the NADW that crosses the equator in the Atlantic upwells south of $50^{\circ} \mathrm{S}$. Updated figure from Döös and Coward [1997], reproduced with permission.

[74] Toggweiler and Samuels [1993b, 1995, 1998] suggested that the Drake Passage effect has fundamental implications for the meridional overturning circulation. The basic idea is that at the latitudes of Drake Passage the return flow of the northward Ekman flow driven by Southern Ocean westerly winds must take place below the depth of the shallowest sill. In their view, given that at these latitudes the densities of the surface northward and deep southward water masses are very different, the only place where these can be connected is the North Atlantic. Hence NADW is viewed simply as the closing, sinking branch of a loop driven by Southern Ocean westerlies in which surface waters are pushed northward by Ekman drift, which, because of the Drake Passage effect, forces deep waters to upwell. The weak stratification in the North Atlantic favors that deep waters are formed there through buoyancy loss at the surface and subsequent sinking. North Atlantic outflow waters are thus nothing but the deep return flow of the surface Ekman transports from the Southern Ocean.

[75] Consequently, the intensity of the inflow and outflow from the Atlantic basin, i.e., the strength of the AMOC, should be largely determined by the strength of the Southern Ocean zonal wind stress component. Strengthening the westerly winds in the Southern Ocean should result in

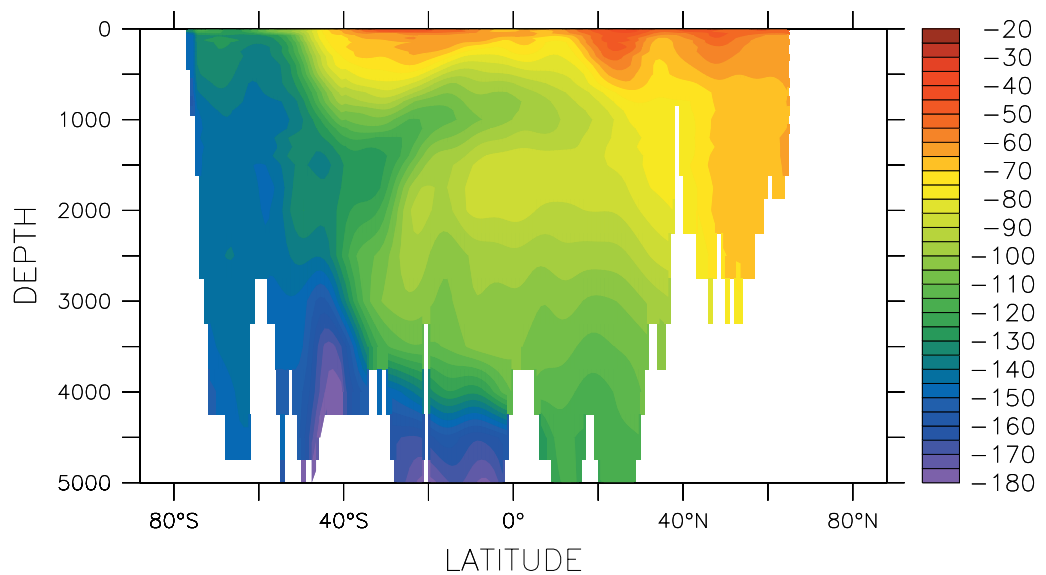

Figure 6. Atlantic south to north cross section along $28^{\circ} \mathrm{W}$ of the natural radiocarbon distribution $\left(\Delta^{14} \mathrm{C}\right)$ in parts per thousand. The low $\Delta^{14} \mathrm{C}$ concentrations at the surface of the Southern Ocean suggest strong upwelling there. Data are from the World Ocean Circulation Experiment (WOCE) [Key et al., 2004]. 


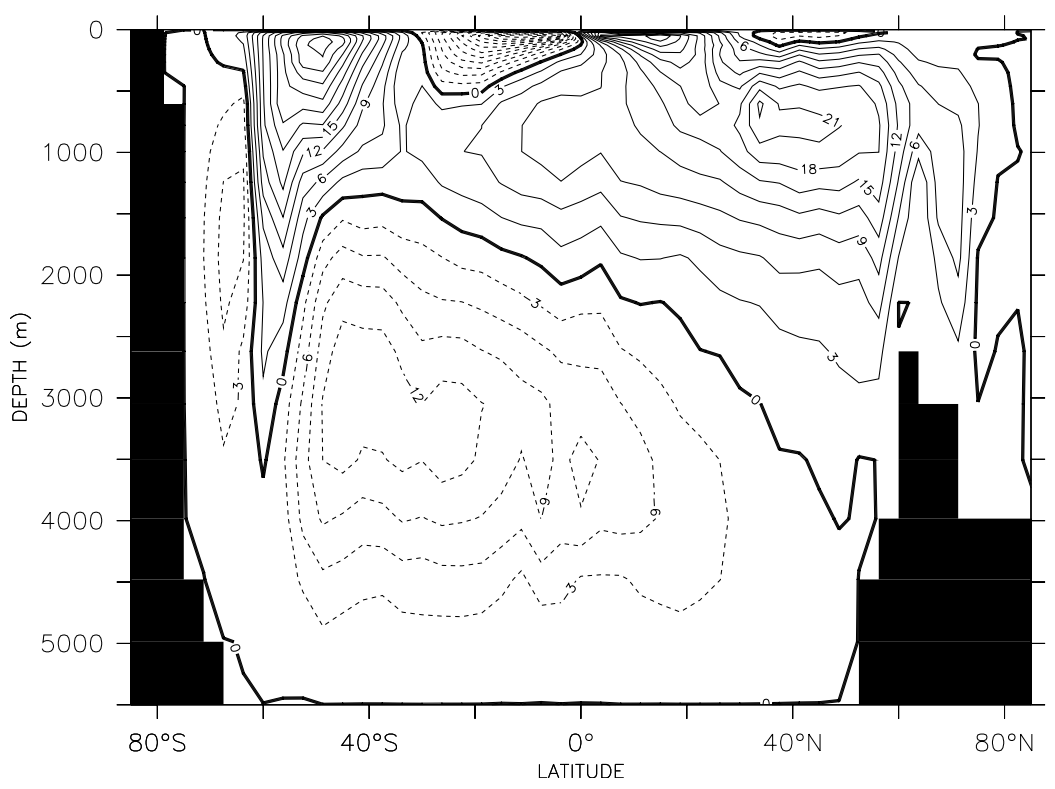

Figure 7. Global stream function of the zonally integrated meridional overturning circulation for the same simulation as in Figure 3. A total of about $38 \mathrm{~Sv}$ of deep water is formed. The deepwater formation rates in the North Atlantic (see Figure 3) and in the Southern Ocean are almost equal. The overturning cell in the upper waters of the Southern Ocean is called the Deacon cell as described in section 4.2.

enhanced Atlantic overturning circulation via enhanced northward Ekman transport. This hypothesis has been tested with an OGCM, which shows, indeed, a large sensitivity of NADW and its outflow at $30^{\circ} \mathrm{S}$ to the zonal component of the wind stress in the Southern Ocean [Toggweiler and Samuels, 1993a, 1995]. Nevertheless, this finding has been questioned on the basis that the large sensitivity results from using restoring surface boundary conditions that impede North Atlantic temperatures to respond to ocean circulation changes: A model that took into account, albeit in a simplified way, the negative temperature feedback of the AMOC shows much smaller sensitivity of the NADW outflow to changes in the Southern Ocean winds [Rahmstorf and England, 1997].

[76] Moreover, according to Toggweiler and Samuels [1993b, 1995], because of the Drake Passage effect, the northward Ekman flow must return south via the North Atlantic and below the depth of the shallowest sills. However, observations [Schmitz, 1995, 1996] indicate that the northward flow at about $40^{\circ} \mathrm{S}$ is, in fact, much smaller than the Ekman transport, which implies that a substantial part of the return flow takes place at shallow depths, i.e., above topography. In accordance with this, inverse model results [Sloyan and Rintoul, 2001b] and high-resolution ocean models [Killworth and Nanneh, 1994; Hallberg and Gnanadesikan, 2007] indicate considerable poleward transport at layers above topography. Rintoul et al. [2001] and Gnanadesikan and Hallberg [2002] describe how this can be achieved. As portrayed by the meridional overturning stream function (Figure 7), in ocean models a substantial amount of the southward Ekman return flow takes place within the Southern Ocean in the so-called Deacon cell. A very important property of this cell, as indicated by results from high-resolution models, is that it is associated with very little density changes [Döös and Webb, 1994]. This implies that if plotted in neutral (density) coordinates, the Deacon cell vanishes, while showing up in height coordinates. If the southward return flow occurs above topography at the same density as the Ekman flow (Rintoul et al.'s [2001] case I), there will be no overturning cell in density coordinates. The density layers below will also contain similar flows; water particles would describe cells in a given isopycnal layer such that flows in opposite sense of

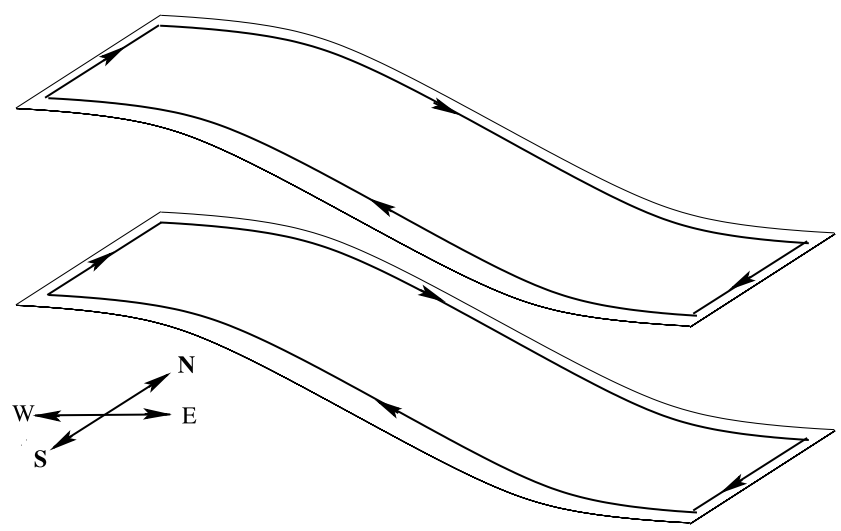

Figure 8. Schema showing how the Deacon cell vanishes. Thin lines represent constant density surfaces, called isopycnals; thick lines represent the trajectories of water particles on the isopycnals. If a zonal average is taken on the isopycnals, the circulation vanishes on each isopycnal, and no net meridional circulation remains. If the zonal average is taken on levels, then all meridional circulation cancels out too, except on the topmost and the lowest horizontal surfaces. Thus in this zonally averaged picture a spurious top-to-bottom overturning cell remains. 
two adjacent density layers cancel (Figure 8). In height coordinates the net flow at all intermediate depths cancels except at the very surface and below topography. It can be shown that this case is associated with the existence of eddies, either stationary or transient [Rintoul et al., 2001]. Thus a substantial amount of the northward Ekman transport recirculates back southward, and the upwelling can take place above topography because of the presence of eddies.

[77] Hallberg and Gnanadesikan [2007] have recently shown that the structure of the overturning cells in the Southern Ocean varies considerably with the model's resolution. Basically, the surface poleward transport increases considerably, and extends farther southward, with higher resolution. Furthermore, they have also shown that the sensitivity of the AMOC to wind stress changes markedly with the ocean model resolution. In coarseresolution models, changes in the Ekman transport produce comparable changes in the overturning, with a large fraction of the enhanced Ekman transport supplied by deep upwelling. The eddy kinetic energy responds linearly to changes in the wind stress, so that for higher resolutions a large fraction of the Ekman transport changes are compensated by the eddy-induced transport, drawing from lighter waters than does the mean overturning. These results, together with those pointed out in the previous paragraph, thus suggest that the sensitivity to the Southern Ocean winds might depend on the model employed, in particular, its resolution, background climate, and feedback strength, and that, even in the case in which most of the upwelling of NADW takes place in the Southern Ocean, the Drake Passage effect might not necessarily result in such a strong link between Southern Ocean westerly winds and NADW.

[78] Finally, as long as the surface westerly winds over the Southern Ocean are present in a similar way to today's, there will indeed be a northward Ekman transport of $30 \mathrm{~Sv}$. However, even in the extreme case in which all this flow were associated with deep upwelling and a net return flow originating from below the depth of about $2000 \mathrm{~m}$ (Rintoul et al. [2001]'s case II), this does not necessarily imply the existence of an AMOC such as the present one, with deepwater formation in the North Atlantic. Climate models suggest the existence of two stable equilibria of the AMOC through the positive salinity advection feedback (see section 6.2 and Manabe and Stouffer [1988], Rahmstorf [1996], and Rahmstorf et al. [2005]), one with strong downwelling in the North Atlantic and one without. It is thus the possibility of having localized downwelling in the North Atlantic that determines the specific shape of the overturning cell (section 5). Although from Sandström's theorem (section 2) it is clear that surface buoyancy fluxes do not drive the deep overturning circulation; through their influence on deepwater formation they play a central role in the amount of volume transported by the overturning circulation as well as its shape. Thus they should be considered as necessary for the existence of a deep AMOC [Huang, 2004].

\subsection{Winds: Energy Requirements, Sources, and Pathways}

[79] The scenario in which most of the deep waters upwell through wind-driven upwelling in the Southern Ocean implies that the dominant energy input driving the AMOC is the direct large-scale kinetic energy input through the winds to the large-scale circulation. As mentioned in section 3, one of the first estimates of mechanical energy input by the surface winds to the ocean circulation was that by Lueck and Reid [1984], who estimated 7-36 TW. It has been assumed that most of this energy probably remains in the surface, leading to turbulent mixing and surface gravity waves, and that only a very small fraction goes to the largescale ocean circulation [Wunsch and Ferrari, 2004, and references therein]. Wang and Huang [2004a] have recently considered the work done by the large-scale, quasi-steady surface currents. As described in section 3, splitting the horizontal surface velocity into its geostrophic and ageostrophic components, we have (see section 3.2)

$$
W_{\text {wind }}^{l s}=\boldsymbol{\tau} \cdot \mathbf{u}_{\mathbf{0}, \mathbf{g}}+\boldsymbol{\tau} \cdot \mathbf{u}_{\mathbf{0}, \mathbf{a}},
$$

where for simplicity we have dropped the overbar in all quantities that refer to large-scale long-term averages. The first term on the right-hand side represents the work done by the surface winds on the geostrophic flow. Fofonoff [1981] and Oort et al. [1994] estimated this contribution to be about 2 TW; Wunsch [1998], however, estimated only 1 TW and showed that the largest inputs take place in the Southern Ocean and northern western boundary current regions (Gulf Stream, North Atlantic, and Kuroshio currents). The second term is the work on the ageostrophic flow, estimated as about $3 \mathrm{TW}$, resulting from about $2.4 \mathrm{TW}$ from subinertial periods [Wang and Huang, 2004a] and 0.5-0.7 TW from inertial periods [Watanabe and Hibiya, 2002; Alford, 2003]. The largest inputs are found in the Southern Ocean as well. Wang and Huang [2004a] indicate that part of the energy from subinertial periods contributes to sustain mixing and turbulence below the Ekman layer but most is likely to contribute to mixing and turbulence within the Ekman layer, maintaining the stratification of the upper ocean.

[80] The input of mechanical energy by the winds on the general circulation is thus essentially the work done by the wind stress on the geostrophic flow, i.e., the first term of the right-hand side in equation (36), which actually forces the interior circulation indirectly through the Ekman layer [Fofonoff, 1981; Wang and Huang, 2004a]. This can be seen by considering the kinetic energy balance for the Ekman layer [Wang and Huang, 2004a]:

$$
E_{t}=W_{\text {wind }}^{l s, e}-P-D,
$$

where $E_{t}$ is the total kinetic energy of the Ekman layer, $W_{\text {wind }}^{l s, e}$ is the rate of wind energy input in the Ekman layer, given by

$$
W_{\text {wind }}^{l s, e}=\boldsymbol{\tau} \cdot \mathbf{u}_{\mathbf{0}, \mathbf{g}}+\boldsymbol{\tau} \cdot \mathbf{u}_{\mathbf{0}, \mathbf{e}},
$$




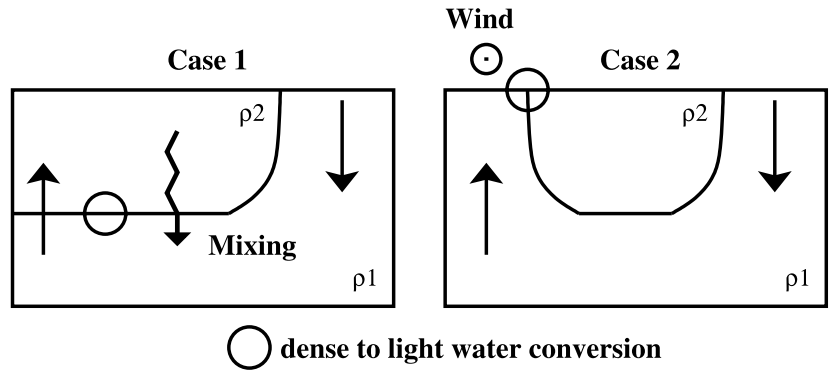

Figure 9. Sketch of the two extreme cases: "only diapycnal mixing" (case 1) and "only wind-driven upwelling" (case 2). The sketches represent highly simplified meridional sections, with NADW formation at the right (northern) end. The curved line indicates the thermocline that separates denser $\left(\rho_{1}\right)$ from lighter $\left(\rho_{2}\right)$ waters. The open circles indicate regions of dense-to-light conversion of water masses. In the wind-driven case 2 the Southern Ocean westerly winds are represented by a circle with a dot inside. Straight arrows indicate volume transport, while the zigzag arrow stands for downward heat flux due to diapycnal mixing.

where $\mathbf{u}_{\mathbf{o}, \mathbf{e}}$ is the surface Ekman flow, $P$ is the pressure work by the current integrated over the Ekman layer, and $D$ is the dissipation rate. As shown by Wang and Huang [2004a], because the geostrophic flow is normal to the pressure gradient, the surface pressure work within the Ekman layer is simply $\boldsymbol{\nabla} p_{s} \cdot \mathbf{u}_{\mathbf{e}}$, where $p_{s}$ and $\mathbf{u}_{\mathbf{e}}$ are the surface pressure and the Ekman velocity, respectively. Integrating over the Ekman layer, assuming constant pressure gradients and taking into account the expression for the geostrophic flow, we have

$$
P=\boldsymbol{\nabla} p_{s} \cdot \mathbf{U}_{\mathbf{e}}=\boldsymbol{\tau} \cdot \mathbf{u}_{\mathbf{o}, \mathbf{g}},
$$

where $\mathbf{U}_{\mathbf{e}}$ is the Ekman velocity integrated over the Ekman layer. Thus the surface pressure work integrated over the Ekman layer is equal to the work done by the wind stress on the geostrophic flow [Gill et al., 1974; Wang and Huang, 2004a; Gnanadesikan et al., 2005]. Inserting (38) and (39) into (37), the kinetic energy balance is simply

$$
E_{t}=\boldsymbol{\tau} \cdot \mathbf{u}_{\mathbf{o}, \mathbf{e}}-D .
$$

Wind stress energy input into the ageostrophic current is thus used to maintain the Ekman spiral against dissipation in the Ekman layer [Wang and Huang, 2004a]. Wind stress work on the surface geostrophic currents is converted to pressure work by the current over the Ekman layer, which is related to the GPE energy generated by Ekman pumping: Divergence of the Ekman layer generates vertical velocities (Ekman pumping or suction, including coastal upwelling), which perform work against the hydrostatic pressure field, contributing to generation of GPE in the ocean. Thus the work done by the wind on the geostrophic flow is converted into large-scale kinetic energy, which is then transferred into large-scale GPE [Gill et al., 1974; Wunsch, 1998; Wang and Huang, 2004a; Wunsch and Ferrari, 2004; Huang et al., 2006].
[81] As shown by Toggweiler and Samuels [1998], there are two regions of net kinetic to GPE conversion. The first one is indeed the subtropical gyres, because of Ekman pumping of light surface waters. Gnanadesikan et al. [2005] indicate that this is the dominant driving term in realistic general circulation models. Yet Toggweiler and Samuels [1998] point out GPE generation in this region almost cancels out with its drawdown through equatorial upwelling. The second region is the Southern Ocean, where surface divergence leads to the upwelling of deep, dense waters. Ivchenko et al. [1997] also report that upwelling is an important source of GPE in the FRAM model and that in high-resolution OGCMs there is always a net conversion of kinetic energy to GPE.

[82] This is quite a different situation from the classical upwelling-diffusive balance, in which turbulent kinetic energy is converted to GPE, which is then converted into large-scale kinetic energy and eventually dissipated through friction. Munk and Wunsch [1998], Wunsch, [1998], and Wunsch and Ferrari [2004] assume the wind energy input to the ocean general circulation contributes to the global MOC through abyssal mixing up to a total of about 2 TW required if most of the deep water upwells at low latitudes (section 3). However, much less mixing would be required if all or most upwelling were wind driven in the Southern Ocean: virtually only that necessary to mix AABW. Dissipation would be balanced by the work done by winds on the large-scale circulation. In this case the sinking and upwelling water masses would have very similar densities; in the limit of no vertical mixing the second term on the lefthand side in equation (26) vanishes and $\langle\bar{w} \bar{b}\rangle=0$. The conversion of deep dense water to surface light water would take place at the surface of the Southern Ocean (Figure 9, case 2). This was indicated by Webb and Suginohara [2001a, 2001b], who revisited the energy requirements to sustain deepwater formation, taking into account the density structure in the Southern Ocean and the fact that most deep water apparently upwells there. They argue that the total of 25-30 Sv of deep plus bottom waters, which, as Munk [1966] and Munk and Wunsch [1998] assumed, must upwell to the surface, is an overestimate. This would mean that the estimate of about $2 \mathrm{TW}$ required to sustain mixing is too high. The point of Webb and Suginohara [2001a, 2001b] is that not all $30 \mathrm{~Sv}$ need to upwell through mixing to the surface. They consider separately the two MOC cells, the AABW cell and the NADW cell (see Figures 10 and 11). AABW must be raised by mixing to the NADW level. Beyond that, as discussed in section 4.2, deep water is brought to the surface by wind-driven upwelling. In the NADW cell, 9-12 Sv of deep water upwell in the Southern Ocean to the surface via Ekman suction. The rest, about 5$8 \mathrm{~Sv}$, is upwelled by mixing. For this latter mixing, Webb and Suginohara [2001a] estimate that an energy flux of $0.6 \mathrm{TW}$ is required. Even if the mixing energy for the AABW conversion is added, the total mixing energy required is likely to stay below the $\sim 2 \mathrm{TW}$ that are available (see section 3). An inverse analysis of hydrographic sections in the Southern Ocean [Sloyan 


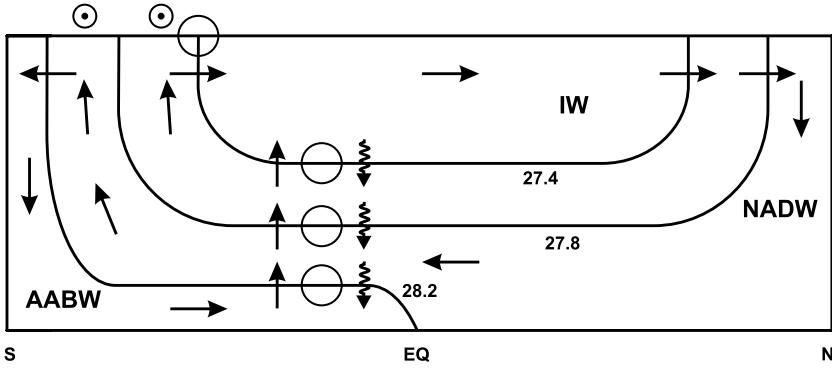

Figure 10. Schema of the AMOC. The two cells, AABW and NADW, are driven by both diapycnal mixing and winddriven upwelling. Above the levels of NADW are the lighter Intermediate Waters (IW). Lines indicate isopycnal surfaces; numbers indicate the respective neutral densities. The neutral density differs only slightly from the potential density but represents isopycnal motions more precisely. See Figure 11 for the observed position of the isopycnals. Other symbols are the same as in Figure 9. For the AABW cell the dense-to-light conversion occurs at depth through diapycnal mixing only. For the NADW cell the dense-tolight conversion happens at depth as well as at the surface. For both cells the light-to-dense conversion is due to buoyancy fluxes and entrainment at high latitudes. The choice of the isopycnals is the same as Figure 13 of Sloyan and Rintoul [2001a].

and Rintoul, 2001a] as well as an analysis of the surface fluxes [Speer et al., 2000] leads to the same conclusion that both diapycnal mixing and wind-driven upwelling are driving the AMOC. The energy budget is closed by including the required energy input for wind-driven upwelling.

\section{THE ROLE OF DEEP WATER FORMATION}

[83] At its surface the ocean exchanges heat, fresh water, and momentum with the atmosphere. Having discussed the role of energy and momentum fluxes for the large-scale circulation in sections 3 and 4, we now concentrate on the heat (latent, sensible, and radiative) and freshwater (evaporation, precipitation, runoff, sea ice, and glacier meltwater) fluxes that are subsumed as buoyancy fluxes. From Sandström's theorem (section 2) it is evident that surface buoyancy fluxes cannot provide the energy that is necessary to drive the AMOC. However, they are essential for deepwater formation, i.e., the conversion of surface water masses to deep waters by raising their density through cooling and/or increasing salinity. The dense deep and bottom water masses in the oceans are formed in the regions of very high surface density. In other words, the surface buoyancy fluxes contribute to setting the properties of the deepwater masses. While the driving processes set the rate of upwelling of a steady state MOC, this does not have to result in an interhemispheric overturning circulation in the sense discussed so far in this review. It is the deepwater formation (DWF) processes that set the interhemispheric shape and the strength of the overturning cell. As mentioned in section 4.2, surface buoyancy fluxes should be considered as necessary for the existence of a deep MOC in the Atlantic [Huang, 2004].

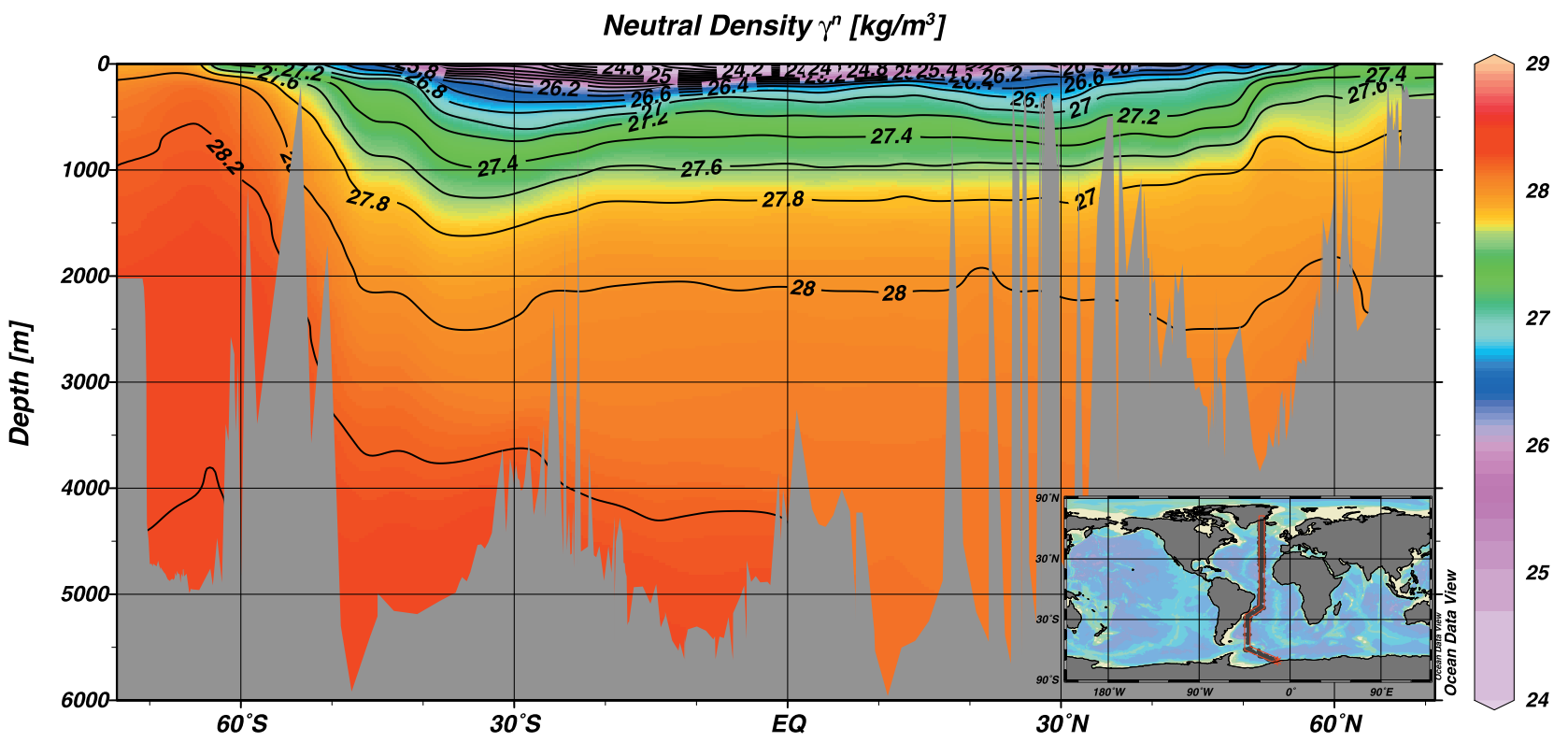

Figure 11. Atlantic south to north cross section of neutral density $\gamma^{n}$ from WOCE data [Schlitzer, 2000]. The inset shows the geographical position of the section. Wind-driven upwelling in the Southern Ocean occurs for waters of $27.4<\gamma^{n}<28.0$ (see Figure 10). AABW, the densest water mass, is found at $\gamma^{n}>$ 28.2. NADW typically has $27.7<\gamma^{n}<28$.0. In the interior ocean, diapycnal mixing leads to an upwelling of AABW to NADW levels and of part of the NADW to thermocline depth $\left(\gamma^{n} \leq 27.4\right)$. Since in most cases the underlying data were not observed during the DWF season, the outcropping of the respective isopycnals is not seen here. However, the overflow from Denmark Strait forms a boundary current on the shelf of Greenland at about $1000 \mathrm{~m}$ depth, just below the $\gamma^{n}=27.8$ isopycnal in this section. 
Thus they also strongly determine changes in the NADW cell of the AMOC, e.g., during the last glacial period (section 6.1) or, possibly, in the next decades and centuries (section 6.4).

\subsection{Deepwater Formation in the North Atlantic}

[84] In the North Atlantic, there are several processes that lead to DWF. Open ocean deep convection and other turbulent vertical mixing processes go along with the actual heat loss to the atmosphere. Salt input occurs when sea ice freezes because strongly saline water (brine) is released during this process. Sill overflows, entrainment, and sinking in the boundary currents are associated with the actual downward motion.

[85] Open ocean deep convection is observed in the Labrador Sea and less frequently in the Greenland Sea [Marshall and Schott, 1999]. It can reach depths of $2000 \mathrm{~m}$ in the Labrador Sea and $3000 \mathrm{~m}$ in the Greenland Sea. A deep convection event starts with preconditioning. Cyclonic wind forcing pushes the surface waters away from the central Labrador Sea toward the coasts, and this happens in a comparable way in the Greenland Sea. This surface divergence leads to upwelling of denser deep waters, which can be seen in transects as a doming of the isopycnals [Lilly et al., 1999]. Together with buoyancy loss to the atmosphere, this weakens the vertical density gradient. The actual convection event is initiated when an individual weather system results in a strong local heat loss and removes the remaining weak density stratification in the ocean. The consequence is a vigorous vertical mixing, with cold surface waters sinking and warmer deep waters rising. Such an open ocean convection event occupies and area of about $50 \mathrm{~km}$ diameter and lasts for only a few days. In the Greenland Sea, brine rejection from sea ice formation additionally increases the surface layer density. Open ocean convection also occurs in the Irminger Sea. Yet it is not established so far whether this plays a role for the AMOC [Bacon et al., 2003; Pickart et al., 2003].

[86] The net downward motion of waters during a convective event is negligible. After convection, eddies mix the cold and dense waters in the center of the convection area with waters in the boundary currents. It is still an open question where exactly the postconvection sinking occurs. Recent modeling studies [Spall, 2004; Straneo, 2006] suggest that the sinking mainly occurs at the lateral boundaries of the Labrador and Greenland seas. Other studies suggest that there is an eddy-induced overturning with sinking in the convection region [Khatiwala et al., 2002].

[87] While deep convection down to about $2000 \mathrm{~m}$ is necessary for deepwater formation in the Labrador Sea, the situation in the Nordic Seas is different. Any deepwater mass circulating from the Nordic Seas into the North Atlantic has to flow over one of the two sills of the Greenland-IcelandScotland ridge (roughly sketched in Figure 2). Their depths are $630 \mathrm{~m}$ in the Denmark Strait and $840 \mathrm{~m}$ in the Faroe Bank Channel. Hence deepwater formation down to these depths is sufficient for the necessary buoyancy loss to create the overflow waters that are involved in the AMOC [Meincke et al., 1997]. It is observed that these intermediate depths are ventilated regularly by widespread, wintertime mixed layer deepening [Watson et al., 1999]. Experiments indicate that year-round turbulent mixing in the upper $\sim 1000 \mathrm{~m}$ is rather strong [Garabato et al., 2004a]. These processes are associated with strong heat loss of middepth Atlantic waters. Other relevant processes for DWF are horizontal eddy mixing, which dilutes the Atlantic Water on its way north, and shelf convection initiated by brine release. The freshwater budget of the Nordic Seas is determined by exchanges with the Arctic Ocean [see, e.g., Weaver et al., 1999; Furevik et al., 2007].

[88] Assessing the rates of deep and bottom water formation is a challenging task. Because the very slow vertical motion of water masses associated with the AMOC eludes detection even when using modern current meters, there is no direct way to quantify the amount of water downwelling at high latitudes. Data on transient tracers such as tritium $\left({ }^{3} \mathrm{H}\right)$, chlorofluorocarbons (CFCs), and others from worldwide ocean surveys (e.g., Geochemical Ocean Sections Study, Transient Tracers in the Ocean, and World Ocean Circulation Experiment) allow an indirect estimate of NADW formation rate of about $15 \pm 2 \mathrm{~Sv}$ [Broecker and Peng, 1982; Ganachaud and Wunsch, 2000]; Talley et al. [2003] estimate $18 \pm 5 \mathrm{~Sv}$ from hydrographic data.

[89] The contributions of the different DWF sites to the total amount of NADW formation are comparable. Estimates of the formation rates are based on direct measurement of the overflow currents [Dickson and Brown, 1994] and on inference from tracer distributions [Lab Sea Group, 1998; Smethie and Fine, 2001; Khatiwala et al., 2002], with an error of about 30\%: (1) overflow over the GreenlandIceland sill in Denmark Strait, 2.4-2.9 Sv; (2) overflow over the Iceland-Scotland sill, 2.4-2.7 Sv; and (3) DWF in the Labrador Sea, 2-4 Sv.

[90] To obtain the 15-18 Sv of southward NADW volume transport, additional processes have to be taken into account. Notably, entrainment of waters along the currents' paths adds considerable volume to the sill overflows.

\subsection{Deepwater Formation in the Southern Ocean}

[91] In contradistinction to the strong convection sites in the open northern Atlantic the deep water in the Southern Ocean is formed mainly along the continental slope of Antarctica. During the winter in the Southern Hemisphere, large amounts of sea ice are formed around Antarctica. Because of the rejection of brine they leave behind dense water masses near the surface. Large ice-free patches in the sea ice cover, called polynyas, play a central role in this process also because of strong heat loss [Maqueda et al., 2004]. The buoyancy loss makes the waters sink to the bottom of the continental shelf. If the amount is large enough, it reaches the shelf break and flows down the continental slope. During this process its volume is increased significantly by entrainment of less dense waters, and bottom water is formed [Baines and Condie, 1998]. Specific details of the bottom topography with small spatial 
structures (on the order of $10 \mathrm{~km}$ ), such as submarine canyons, are central to these processes, because they determine the degree of entrainment of water masses that is possible because of the roughness of the topography. Therefore quantitative estimates of the amount of deep water formed in the Southern Ocean are difficult to obtain. However, they are crucial for global budgets of the vertical mass transport, which lead to global estimates of the required energy that sustains the global overturning circulation. Interactions between $\mathrm{AABW}$ and NADW are addressed in section 6.3 .

[92] Assessments of the AABW formation rate based on the distribution of $\Delta^{14} \mathrm{C}$ and $\mathrm{PO}$ 娄 give values comparable with those in the Northern Hemisphere. PO ${ }_{4}^{*}$ concentrations, lowest in the North Atlantic (about $0.75 \mu \mathrm{mol} \mathrm{L}^{-1}$ ) and highest in the Southern Ocean (about $1.95 \mu \mathrm{mol} \mathrm{L}^{-1}$ ), show a relatively uniform distribution within the deep Pacific and Indian oceans with values of about $1.3 \mu \mathrm{mol} \mathrm{L}{ }^{-1}$. Assuming northern and southern water masses to be equally well mixed in these ocean basins, Broecker and Peng [1982] found a formation rate of southern deep and bottom water of about 15 Sv. More recent CFC data analyses, however, contradict these results. Orsi et al. [1999] found that only about $5 \mathrm{~Sv}$ of AABW forms all along Antarctica. To reconcile these different assessments, Broecker et al. [1999] assumed the AABW formation rate to be highly variable during the last 1000 years. They speculate that AABW formation could have been much higher during the Little Ice Age (about 16th to 19th century) than today. Orsi et al. [1999] and Ganachaud and Wunsch [2000] argue that values derived from $\mathrm{CFC}$ and $\mathrm{PO}_{4}^{*}$ are not conflicting because they refer to different density classes of water masses. Whereas the $\mathrm{PO}_{4}^{*}$-based value of $15 \mathrm{~Sv}$ is associated with the formation of water masses crossing the $\gamma_{n}=28.11$ isoline below $1500 \mathrm{~m}$, the value of $5 \mathrm{~Sv}$, derived from CFC data, is associated with production of waters recently exposed to the atmosphere. Entrainment of NADW into the relatively freshly formed Antarctic deep and bottom water coming from the sea surface could explain the steady increase in the formation rate toward greater depth. As a consequence they argue that there is no necessity for the entire amount of $15 \mathrm{~Sv}$ of AABW to upwell to the sea surface. This finding is in line with new assessments of the global amount of upwelling deepwater masses. Earlier studies [Munk and Wunsch, 1998] assumed $30 \mathrm{~Sv}$ of global deepwater formation, about $15 \mathrm{~Sv}$ each from the northern North Atlantic and the Southern Ocean. More recently, Webb and Suginohara [2001b] proposed a maximum amount of $20 \mathrm{~Sv}$ that have to reach the sea surface, as discussed in section 4.

\section{STABILITY OF THE AMOC}

\subsection{Past AMOC Shifts}

[93] Analysis of sediment cores and corals provides a wealth of information on past ocean circulation and shows that it has undergone major changes during the past 120,000 years (reviewed by Rahmstorf [2002]). Time slice compilations suggest that at different times, three distinct circulation modes have prevailed in the Atlantic [Sarnthein et al., 1994]. These have been labeled the stadial mode, interstadial mode, and Heinrich mode, based on their occurrence during stadial (cold) and interstadial (warm) phases of glacial climate and during Heinrich events (see below). In the interstadial mode, North Atlantic Deep Water formed in the Nordic Seas; in the stadial mode it formed in the subpolar open North Atlantic (i.e., south of Iceland); and in the Heinrich mode, NADW formation all but ceased, and waters of Antarctic origin filled the deep Atlantic basin. This grouping of the data into three distinct modes is a somewhat subjective interpretation; the data, however, strongly suggest that latitude shifts of convection (between the Nordic Seas and the region south of Iceland) have occurred [e.g., Alley and Clark, 1999] and that at certain times NADW formation was interrupted [Keigwin et al., 1994]. There is also solid evidence now for a link between these ocean circulation changes and abrupt changes in surface climate [see Clark et al., 2002].

[94] The most dramatic abrupt climate changes are the Dansgaard-Oeschger (DO) warm events, with a warming that can exceed $10^{\circ} \mathrm{C}$ within a decade or so [Severinghaus et al., 2003]. Proxy data show that the South Atlantic cooled when the North Atlantic warmed [Voelker et al., 2002], which is indicative of an ocean heat transport change, and that salinity in the Irminger Sea increased strongly [van Kreveld et al., 2000], indicative of saline Atlantic waters advancing northward.

[95] Another type of abrupt change is the Heinrich events; sediment data indicate a large discharge of icebergs into the northern Atlantic [Heinrich, 1988] and a shutdown of NADW formation [Keigwin et al., 1994]. These events are thought to have been caused by ice sheet instability; the iceberg discharge would then have provided a large freshwater forcing to the Atlantic (of the order of $0.1 \mathrm{~Sv}$ [Hemming, 2004]). This is an important difference to the DO events, for which no large forcing of the ocean is known.

[96] At the end of the last glacial period, as the climate warmed and ice sheets melted, the ocean circulation went through a number of oscillations that may be explained by meltwater input, i.e., the Younger Dryas and the $8.2 \mathrm{kyr}$ cold event.

[97] Many aspects of these abrupt events found in proxy data have been reproduced in model simulations. Large freshwater input, such as that associated with Heinrich events, has been shown in many models to shut down NADW formation [e.g., Schiller et al., 1997]. While the earlier attempts to simulate abrupt events were based on present-day climate states in models, more recently, glacial climate states have become available as a basis for simulations of abrupt ocean circulation change [Ganopolski and Rahmstorf, 2001b]. Latitude shifts in convection can be triggered by small forcing if the ocean circulation is close to a threshold; the resulting climate change patterns resemble DO events [Ganopolski and Rahmstorf, 2001a]. Such convection shifts could be timed by solar variability [Braun 
et al., 2005]. The climate response to freshwater input of the $8.2 \mathrm{kyr}$ event has also been simulated with encouraging results in a number of models [e.g., Bauer et al., 2004].

[98] The variability of the thermohaline ocean circulation during the Holocene after the $8.2 \mathrm{k}$ event is discussed by Keigwin and Boyle [2000]. Variations are clearly much smaller than during glacial times, and the evidence for them is still controversial and not very strong. An important question here is whether cooling during the "Little Ice Age" ( 1500-1900 A.D.) is related to THC changes, but this question remains unresolved.

\subsection{Freshwater Fluxes and Bistability}

[99] The surface fluxes of fresh water give rise to two thermohaline feedbacks. The first one is the "positive salt advection feedback": The AMOC's NADW cell transports salt northward, which maintains the waters' relatively high salinity in the DWF regions in spite of the freshwater input in the northern midlatitudes. Because of the higher density this fosters sinking. Thus there is a positive advective feedback: An ongoing circulation keeps up the deepwater formation, and conversely, with a halted NADW formation, there is no northward salt transport, and hence DWF is suppressed. This advective feedback was described first by Stommel [1961] in a simple two-box model. It gives rise to a parabola-shaped stability diagram that shows a bistability of the overturning with respect to the atmospheric freshwater transport (see Figure 12): For a fixed freshwater flux, there is one stable state with and one stable state without an overturning circulation. A great number of studies have followed Stommel's pioneer work; we mention here, in an exemplary manner, some studying this or similar box models [Rooth, 1982; Lohmann and Schneider, 1999; Monahan, 2002] and some applying it to three-dimensional ocean and climate models [Bryan, 1986; Marotzke and Willebrand, 1991; Tziperman et al., 1994; Rahmstorf, 1995a, 1996]. Overviews of this vast field are given by Weaver and Hughes [1992] and Rahmstorf et al. [1999].

[100] While the basin-size density gradients (see section 6.3) determine the advective feedback, a second, "convective" feedback concerns one specific deepwater formation site. There is a net freshwater input at the DWF sites in the North Atlantic. As long as convection happens regularly, the inflowing fresh water becomes denser by mixing with the deep saline waters. This keeps the surface density high and thus fosters convection to occur in the following winter. However, once convection has not occurred for a couple of years, because of, e.g., variability in the surface fluxes, then the fresh water accumulates at the convection site. This decreases the surface density and inhibits further convection events. In this way, convection sites may be switched off. The positive convective feedback was described in a two-box model by Welander [1982]; many studies since have used it for the analysis of threedimensional ocean models [Lenderink and Haarsma, 1994, 1996; Rahmstorf, 1994, 1995b; Pierce et al., 1995] as well of observed data [Kuhlbrodt et al., 2001].

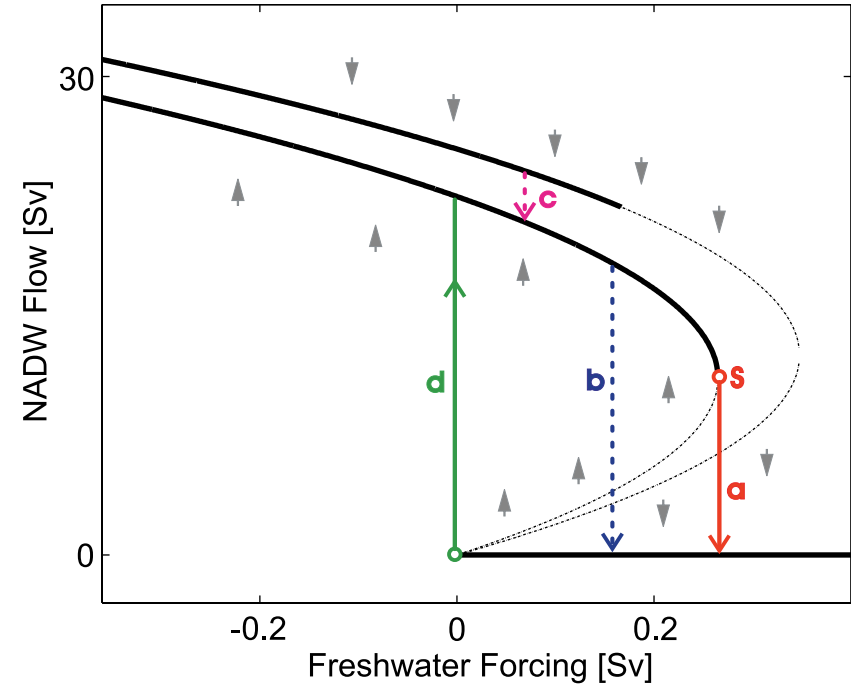

Figure 12. Schematic stability diagram for the volume flux of the NADW cell of the AMOC from a modified version of the Stommel [1961] box model. Solid black lines indicate stable equilibrium states, and dotted black lines indicate unstable states. Changing the freshwater flux into the North Atlantic shifts the position on the branches and may trigger transitions. These transitions are indicated by labeled arrows: a, NADW cell spin down due to advective feedback; b, shutdown due to the convective feedback; $\mathrm{c}$, transition between different deepwater formation sites induced by the convective feedback; and $\mathrm{d}$, restart of the NADW cell. " $S$ " marks the Stommel bifurcation point beyond which no North Atlantic Deep Water formation can be sustained. Adapted from Rahmstorf [2000, Figure 2] with kind permission of Springer Science and Business Media.

[101] Both the advective and the convective feedback imply a possible bistability: Under constant boundary conditions, there can be an "on" and an "off" state. Stommel's model for the large-scale MOC assumes that the boxes in his model are always well mixed, so surface buoyancy fluxes directly affect the deep flow. We need to reconsider Stommel's bistability if wind-driven upwelling (section 4) plays a major role in driving the MOC.

\subsection{Role of the Drivers for the Stability of the AMOC}

[102] How do the stability properties of the AMOC change in dependence on the driving mechanism? How independent of the driving mechanism is the role of deepwater formation? We consider here the insight provided by simple conceptual models based on an equation system that is analytically solvable and yet is thought to capture the main physics of the real system. Most of those models consider a volume flux $\Psi$ of the AMOC's NADW cell:

$$
\Psi \propto D \Delta \rho,
$$

where $\Delta \rho$ is a meridional density difference and $D$ is the pycnocline depth or scale of the vertical flow. One of the first of such conceptual models is the one devised by Stommel [1961], consisting of a high- and a low-latitude 
box whose density difference determines the volume flux of the NADW cell. This model does not consider the energetics of the flow. Rather, the AMOC is simply assumed to be proportional to the meridional density difference between the boxes, which is determined by the surface heat and freshwater fluxes and the flow itself.

[103] By contrast, following theories for the structure of the thermocline, Bryan and Cox [1967] derived a scaling for the meridional circulation based on geostrophy and on advective-diffusive heat balance leading to a nonlinear scaling with the meridional density difference. Their derivation implies that the vertical scale for the meridional flow, the depth of the pycnocline, is not fixed as in the Stommel [1961] framework and that the driving of the AMOC in the form of diapycnal mixing is explicitly specified. An equation for the zonal velocity $u$ follows from thermal wind balance:

$$
f \partial_{z} u=\frac{g}{\rho_{0}} \partial_{y} \rho
$$

Inserting typical scales for the pycnocline depth $D$ and the meridional extent $L_{y}$ of the flow and with $\Delta \rho$ being the imposed meridional density difference, one obtains for the zonal flows

$$
U=\frac{g}{f \rho_{0}} \frac{\Delta \rho}{L_{y}} D .
$$

[104] At the base of the thermocline the advection-diffusion balance equation (28) is assumed to hold for the density. The assumption behind the pycnocline scaling without wind is that changes in vertical diffusivity only change the depth of the pycnocline but not the density difference [Robinson and Stommel, 1959]. Inserting typical scales into equation 28 provides

$$
D=\frac{\kappa_{v}}{W}
$$

The relation between meridional and vertical flow is governed by vorticity dynamics, expressed through the Sverdrup balance:

$$
\beta v=f \partial_{z} w \quad V=\frac{f}{\beta} \frac{W}{D}
$$

It is assumed that the zonal flow scales like the meridional flow, such that $U L_{y} D=V L_{x} D$. Combining equations (43), (44), and (45) gives an expression for the meridional overturning:

$$
\Psi=V L_{x} D=\left(\frac{g f L_{x}^{2}}{\rho_{0} \beta^{2}}\right)^{1 / 3} \kappa^{2 / 3} \Delta \rho^{1 / 3}
$$

The meridional volume transport is proportional to $\Delta \rho^{1 / 3}$, and it scales like $\kappa_{v}^{2 / 3}$. Hence this derivation is different from the scaling in the Stommel box model with a constant pycnocline depth.
[105] It is important to note that the scaling $\Psi \propto \Delta \rho$ is the result of multiple assumptions. One main assumption is that the pycnocline depth $D$ is determined from advectivediffusive balance and is also the scale for the volume transport. However, in the presence of wind forcing, Ekman pumping creates a "bowl-shaped" structure of the pycnocline as consistent with the theories of the ventilated thermocline and not of vertical mixing. Recently, Marshall et al. [2002] and Radko and Marshall [2004] suggested that lateral eddy fluxes rather than the small-scale mixing at the base of the thermocline are key to maintaining the structure of the pycnocline and balance the downward transport of heat through Ekman pumping.

[106] Apart from that, Rahmstorf [1996] noted that $D$ being independent of the NADW flow rate would be consistent with NADW not upwelling within the Atlantic. He obtains a linear relation of the Atlantic overturning with an interhemispheric meridional density difference in a global OGCM. Also, his hysteresis curves from the OGCM follow closely that of an interhemispheric box model related to the Stommel box model, using a linear scaling with the density difference. In this model it does not matter by what mechanism the water upwells (this being outside the model domain), and the hysteresis behavior is hence independent of the driving mechanism.

[107] The scaling of equation (46) has been extensively tested mostly in single-hemisphere models without wind forcing [Colin de Verdière, 1988; Marotzke, 1997; Zhang et al., 1999], as has been reviewed by Park and Bryan [2000]. For the scaling with diffusivity, power laws with exponents different from 2/3 have been found. Park and Bryan [2000] attributed discrepancies to a significant amount of spurious recirculation in the North Atlantic when the overturning is diagnosed in $z$ coordinates. Park [1999] included the nonlinear mass transport law into Stommel's box model and concluded that this model has different stability properties.

[108] Another assumption of the scaling equation (46) as well as for the Stommel-type box models is that since the meridional density gradient explains only a zonal flow with geostrophy, it scales like the meridional flow. One common illustration to underline this assumption is that as the zonal flow is bounded by continental barriers, it will lead to a secondary meridional flow: The north-south density difference leads to an eastward flow, which piles up water that downwells on the eastern wall. This resulting east-west gradient in the surface elevation then leads to a northward flow [Wright et al., 1995].

[109] Marotzke [1997] analytically derived an expression for the east-west pressure difference and therefore the meridional flow in relation to the north-south surface density difference for a one-hemisphere model without wind forcing and with the assumption that convection takes place in the eastern boundary. A linear relation between some measure of the interhemispheric meridional pressure gradient and the volume flux of the AMOC has been found diagnostically in global OGCMs. Hughes and Weaver [1994] used a measure of the depth-integrated baroclinic 
pressure, defined as the vertical integral of density between the ocean surface and bottom; Thorpe et al. [2001] took the density integrated between the surface and $3000 \mathrm{~m}$.

[110] Gnanadesikan [1999] assumed the north-south pressure difference produces a frictional flow in the western boundary and through that directly related the meridional pressure difference to the meridional flow. He extended the scaling from equation (46) and included two more processes into the conceptual model that would influence the pycnocline depth: Southern Ocean winds through the Drake Passage effect and Southern Ocean eddies. In his framework, northern sinking is balanced by a diffusively driven upwelling in low latitudes and a wind-driven upwelling in the Southern Ocean minus an eddy return flow. Hence he includes the two driving mechanisms explicitly but does not include the salt advection feedback that could lead to nonlinear behavior. His model has been under intense investigation as a possible paradigm for the global MOC [Saenko and Weaver, 2003; Klinger et al., 2003; Kamenkovich and Sarachik, 2004]. However, Levermann and Griesel [2004] discussed that the model does not lead to a linear scaling with the pressure difference $\Delta \rho D$, which seems contradictory to the diagnostic outcome of OGCMs. Griesel and Maqueda [2006] showed that a threedimensional global OGCM is not consistent with Gnanadesikan's [1999] theories, ultimately because the meridional density difference is not independent of the driving processes and the pycnocline depth is less variable.

[111] Griesel and Maqueda [2006] show that there is a linear relation of meridional pressure differences with the Atlantic overturning for simulations with a global OGCM for a variety of values of mixing parameters and surface freshwater forcings. The model behavior is closer to the Stommel model with linear scaling and an Atlantic pycnocline that is constant. This is supported by Mignot et al. [2006], who show that the pycnocline depth is independent of vertical diffusivity.

[112] The question of how a vertical diffusion coefficient depending on the stratification influences the AMOC was addressed by Nilsson and Walin [2001], Nilsson et al. [2003], and Mohammad and Nilsson [2004]. If the total rate of mixing energy supply is kept constant, then there is less vertical mixing in a strongly stratified ocean. In their conceptual and single-hemisphere models this allows for an overturning that increases with a decreasing north-south density gradient in opposition to the Stommel feedback. This intriguing effect, however, could not be reproduced in a coupled climate model [Marzeion et al., 2007].

[113] To our knowledge, no conceptual model exists that would include both driving mechanisms (mixing and winds) as well as potential processes that lead to nonlinear behavior in deepwater formation in a realistic way. Keeling [2002] set up conceptual models of a wind-driven overturning circulation in the limit of very low diapycnal mixing. In this framework, there is a bistability for two circulation states: one with and one without a NADW cell but both with an AABW cell in the abyssal Atlantic. Yet this bistability exists only for a narrow parameter range away from the current climate. Hence these models suggest a stable AMOC. A very demonstrative analytical model was constructed by Samelson [2004]. He sees the overturning circulation as a pump-and-valve system, where the winddriven upwelling is the pump and deepwater formation in high latitudes is the valve. In the case where the buoyancy fluxes inhibit deepwater formation, then there is a regional recirculation of the waters pulled up in the Southern Ocean. While vertical mixing is very weak in both models, they, nevertheless, clearly demonstrate the difference between the energy source and the role of the surface buoyancy fluxes.

[114] How does the Stommel bistability depend on the magnitude of the vertical mixing? In zonally averaged models [Schmittner and Weaver, 2001; Ganopolski et al., 2001] the hysteresis loop shrinks with increasing vertical diffusion. By contrast, Prange et al. [2003] show, in a threedimensional ocean model with fixed climatological forcing, that the Stommel hysteresis increases with vertical mixing and, conversely, disappears in the limit of no vertical mixing. It seems that processes like freshwater transports by the horizontal gyres, while not captured by zonally averaged models, must be taken into account for determining the stability.

[115] The wind-driven upwelling mechanism presented by Toggweiler and Samuels [1993a] has received further theoretical attention in a series of works [Nof, 2000, 2003; DeBoer and Nof, 2004a, 2004b]. By taking integrals of the vertically integrated momentum balance around closed loops, the vertically integrated pressure gradient terms are eliminated and the net northward volume inflow into the North Atlantic is related solely to the Southern Ocean wind stress. This aspect seems particularly important considering the consequences for stability of the AMOC. In an ocean where the overturning circulation would be mainly determined by Southern Ocean westerlies, deepwater formation in the North Atlantic would play a more passive role. If, on the other hand, pressure gradients within the outflow region in the Southern Ocean can vary over a broad range independently of the Southern Ocean wind stress, deepwater formation in the North Atlantic is allowed to vary more independently, and also a stable off-state can exist. Indeed, Griesel and Maqueda [2006] show that zonal pressure gradients in western and eastern boundary currents in the region of the South Atlantic inflow do play an active role, independent of Southern Ocean wind stress and influenced by deepwater formation.

[116] Concerning the relative formation rates of NADW and $\mathrm{AABW}$, it appears that they are anticorrelated in model experiments with variations in the buoyancy fluxes [Klinger and Marotzke, 1999]. In experiments with changes in the wind stress forcing in the Southern Ocean, however, NADW strength and AABW strength vary together [Brix and Gerdes, 2003], although they respond on different timescales. This latter behavior was corroborated by Timmermann and Goosse [2004], who, in an experiment with a coupled ocean-atmosphere model, reduced the global wind stress to zero and found the ocean to have no global MOC. The role of wind-driven upwelling for maintaining 
the global MOC is found in the model experiments by Saenko and Weaver [2004] as well. Apparently, an AMOC that is driven by both mixing and wind-driven upwelling and that is subject to surface buoyancy forcing may show a stability behavior relating to all of these three processes. Their relative roles are, however, still dependent on the employed model.

\subsection{Transient Changes of the AMOC and Their Consequences}

[117] The focus of the present article is on the physical processes that sustain a stable steady state of the AMOC. Model simulations suggest that it takes several millennia to reach such an equilibrium state in the deep ocean because of the long timescales of diffusion. Discussing the balance of energy in this equilibrium is necessary for understanding the AMOC, but since the energy constraint applies on long diffusive timescales, it is less relevant for the transient anomalous response, which, instead, is mainly determined by changes in surface buoyancy fluxes. A surface cooling of previously warmer water can lead to unstable stratification and a flow that obtains its energy by converting available potential energy into kinetic energy not requiring a mechanical energy input. Likewise, a surface warming or freshening in DWF regions can lead to a stable stratification there, interrupting the AMOC temporarily or in some conditions even triggering a transition to another stable state. This is important especially in the reaction to the global climate warming. The weakening of the NADW cell of the AMOC shown by most coupled climate models in scenarios for the 21 st century [Cubasch et al., 2001; Gregory et al., 2005] is mainly caused by heat and freshwater fluxes. Nevertheless, given the role of winds as an energy source to the ocean, the question has been brought up whether transient changes of the AMOC might also be caused by changes in the wind field [Wunsch, 2006].

[118] Some model simulations demonstrate that NADW changes may be transient and reversible. Using a global coupled climate model, Manabe and Stouffer [1994] showed how, in a scenario with quadrupling of the atmospheric carbon dioxide content, the NADW cell almost completely vanishes within 200 years. A continuation of this model run with the constantly high $\mathrm{CO}_{2}$ content [Stouffer and Manabe, 2003] displays a recovery of the NADW cell to the initial strength after 1000 years. In another global coupled climate model a massive freshwater release to the North Atlantic leads to a collapse of the NADW cell, which then recovers to its initial value within 120 years after the freshwater forcing stops [Vellinga and Wood, 2002]. This corroborates a study of Schiller et al. [1997], where in a very similar way the NADW cell recovered within 200 years.

[119] The advective, positive "Stommel" feedback, however, allows for an irreversible shutdown of the NADW cell. This effect, clearly seen in box models (Figure 12), is also found in freshwater flux experiments in many coupled climate models [Rahmstorf et al., 2005]. As the result of a $\mathrm{CO}_{2}$ increase plus an additional freshwater input simulating melting of the Greenland ice sheet, Rahmstorf and Ganopolski [1999] found a state without North Atlantic DWF that lasted for several thousand years. This suggests that a century-long transient weakening might eventually end up in a steady circulation state without a NADW cell. The question is whether global warming will drive the real ocean to this point of no return. From model experiments [Rahmstorf et al., 2005], no distinct answer emerges so far, and experts' assessment of the probability of a breakdown of NADW formation are widely diverging [Zickfeld et al., 2007].

[120] The convective feedback is seen in many coupled climate models as well. For instance, a shutdown of convective activity in the Labrador Sea may lead to a $20 \%$ reduction of the maximum overturning [Wood et al., 1999]. If the same happens in the Greenland Sea, the reduction of maximum overturning in the Nordic Seas is between 27\% [Schaeffer et al., 2002] and over 50\% [Goosse et al., 2002], while the NADW outflow at $30^{\circ} \mathrm{S}$ is reduced by $12-20 \%$. The convective feedback works on timescales of decades, meaning that shifts in the convection sites might already occur in the first half of the 21 st century. The advective feedback has longer timescales, on the order of centuries.

[121] All of the oceanic circulation changes mentioned above have a large effect on climate. A local shutdown of convection could lead to a regional cooling of several degrees [Schaeffer et al., 2002]. A total breakdown of the NADW cell may cool large parts of Europe [Rahmstorf and Ganopolski, 1999]. Seager et al. [2002] have argued that the effect of ocean heat transport on climate has been overstated, but some of their calculations have been shown to be in error, causing an underestimation of the effect of ocean heat transport [Rhines and Häkkinen, 2003]. The model results presented by Seager et al. [2002] show a winter cooling of up to $24^{\circ} \mathrm{C}$ if ocean heat transport is turned off, in line with other modeling results. It should be noted that such a large cooling arises as a result of positive sea ice feedback and applies only to sensitivity experiments where ocean heat transport is turned off in present-day climate. If the ocean circulation changes in response to a strong anthropogenic warming, this warming may partly or fully compensate for any cooling due to reduced ocean heat transport [Rahmstorf, 1997; Wood et al., 2003]. Further implications of AMOC changes are sea level rise [Levermann et al., 2005] and shifts in the tropical precipitation patterns [Vellinga and Wood, 2002]. A comprehensive analysis of the impacts of AMOC changes is given by T. Kuhlbrodt et al. (manuscript in preparation, 2007). The potential for harmful impacts highlights the need to study the transient development of the AMOC along with the question of the driving processes.

\section{DISCUSSION AND OPEN QUESTIONS}

[122] The main aim of this paper is to clarify which physical mechanisms drive the Atlantic MOC (AMOC). Early experiments by Sandström [1908] and theoretical 
work by Sandström [1916] and Bjerknes [1916] suggested that heating and cooling at the surface alone cannot drive a deep overturning circulation; rather, a deep heat source is required for that if other external forcing mechanisms, such as winds, are absent. Sandström was later [e.g., Jeffreys, 1925; Wang and Huang, 2005; Hughes and Griffiths, 2006] repeatedly challenged on the basis that because of downward mixing of heat (by molecular or turbulent diffusion) a deep flow can still be sustained even if heating and cooling occur only at the surface. In our view, however, this argument still leaves Sandström's fundamental insight intact. For the large-scale circulation the downward mixing of heat can be considered as the deep heat source that Sandström's theorem calls for, and Sandström's insight has inspired much further work to identify this deep heat (or buoyancy) source. This is indeed how Sandström [1908] himself saw it when he proposed that downward penetration of heat in the tropics by mixing could drive the deep flow. $\mathrm{He}$ was incorrect, however, in suggesting that salinity differences could drive this mixing.

[123] Jeffreys' [1925] suggestion that turbulent mixing drives the AMOC was established in detail by Munk and Wunsch [1998] and Huang [1999]: Turbulent diapycnal mixing, in balance with slow upwelling, transports heat downward and thus raises the gravitational potential energy of the water masses. Molecular diffusion is very likely not sufficient to obtain a MOC as turbulent and vigorous as observed [Wang and Huang, 2005]. Paparella and Young [2002] established that a fluid that is heated and cooled at the surface only cannot exhibit the kind of turbulence needed to drive a deep flow if there is no other mechanical energy source such as winds and tides. Their definition of turbulence is quite strict; flows could still no longer be stable and laminar in the regime of an extremely high Rayleigh number (e.g., for a strong temperature gradient [Mullarney et al., 2004]). Nevertheless, as pointed out by Wang and Huang [2005], the amount of mechanical energy that would be available from surface thermal forcing is only about $1.5 \mathrm{GW}$, not enough to explain the circulation observed in the ocean. A different possible way of raising the waters from depth is direct wind-driven upwelling [Toggweiler and Samuels, 1993b, 1995, 1998]. Here heat fluxes are not directly involved.

[124] Understanding the mechanism that drives the steady state Atlantic MOC requires understanding its energy source. There are two main candidates for the driving mechanisms: (1) mixing, i.e., energy input to small-scale motion through winds and tides (section 3), and (2) winds, i.e., direct energy input to the large-scale motion (section 4).

[125] We summarize the past sections by considering the two extreme cases sketched in Figure 9. If we assume that large-scale upwelling induced by the surface wind stress is absent, then upwelling must be in balance with diapycnal mixing (case 1). The energy source for the turbulent mixing is internal waves in the ocean that break and dissipate. The internal waves are triggered by (1) surface winds, (2) interaction of tidal waves with the ocean bottom, and (3) the interaction of eddies with the ocean bottom. These inter- actions are especially strong where the bottom topography is rough (underwater ridges, trenches, etc.). However, considering turbulent mixing as the only driver brings up a number of questions. The assumption of uniform upwelling leads to estimates of $\kappa \approx 1 \times 10^{-4} \mathrm{~m}^{2} \mathrm{~s}^{-1}$ for the diapycnal mixing coefficient, given the observed presentday stratification. Yet such large values are not measured uniformly in the ocean's interior. In response to these observations, Munk and Wunsch [1998] reinterpreted their value of $\kappa=1 \times 10^{-4} \mathrm{~m}^{2} \mathrm{~s}^{-1}$ as a basin-wide spatial average, with values 1 order of magnitude lower in the ocean interior and much higher values near rough topography or continental slopes. They estimate that 2 TW mixing energy are necessary to upwell the $30 \mathrm{~Sv}$ of deep waters that are globally formed (section 5). A detailed energy balance [Munk and Wunsch, 1998; Wunsch and Ferrari, 2004] (see section 3.2 and Table 1) reveals that the amount of mixing energy available from the three energy sources is just $2 \mathrm{TW}$. There are, however, large uncertainties in these estimates; thus it is not known whether the energy budget is really closed.

[126] In the alternative idealized case without diapycnal mixing (Figure 9, case 2), kinetic energy input is provided by the winds and is then converted into gravitational potential energy [Toggweiler and Samuels, 1998; Gnanadesikan et al., 2005]. In this theory the deep southward flow of North Atlantic Deep Water is nothing but the return flow of the surface waters in the Ekman layers in the Southern Ocean that are pushed northward into the Atlantic [Toggweiler and Samuels, 1993b, 1995, 1998]. The divergence of the Ekman transports together with the Drake Passage effect, that permits no net meridional geostrophic flow in the Southern Ocean above sill depth, enforces upwelling from depth. Indeed, the analysis of observed tracer distributions indicates strong upwelling of water masses in the Southern Ocean. As can be computed from the curl of the Southern Ocean wind stress [Döös and Webb, 1994], there are potentially around $30 \mathrm{~Sv}$ of upwelling and subsequent northward Ekman transport south of $50^{\circ} \mathrm{S}$, which can be regarded as setting a theoretical upper bound to the strength of the AMOC in the purely wind-driven case. (These $30 \mathrm{~Sv}$ should not be confused with the $30 \mathrm{~Sv}$ of global DWF that Munk and Wunsch [1998] were assuming (section 5).) However, first, these $30 \mathrm{~Sv}$ are partitioned between the Atlantic and Indo-Pacific oceans; second, the larger part of the surface volume transport does not reach the North Atlantic but returns locally at around $40^{\circ} \mathrm{S}$; and, third, not all of the upwelling at Drake Passage latitudes originates from the depth of the NADW outflow. The strength of Southern Ocean eddies determines how much of the water returns southward within the Southern Ocean and upwells at depths shallower than the shallowest sill [Rintoul et al., 2001]. Thus it is not simply the magnitude of the curl of the wind stress that determines the amount of Southern Ocean meridional volume transport that reaches the Atlantic basin. This volume transport also depends strongly on the density structure of the Southern Ocean, which is influenced by eddies and surface heat and freshwater fluxes. 
[127] The picture that emerges is that of an AMOC driven by both mixing and wind-driven upwelling [Webb and Suginohara, 2001a, 2001b; Sloyan and Rintoul, 2001a]. If we consider the two cells of the AMOC (sketched in Figures 10 and 11), then $\mathrm{AABW}$ is first brought up to the levels of NADW by mixing and is upwelled from there to the surface by the wind. By contrast, in the NADW cell, part of the volume flux is upwelled by the wind, and the rest is upwelled by diapycnal mixing. Quantitative estimates of the partition between mixing-driven upwelling and wind-driven upwelling are still rather rough [Webb and Suginohara, 2001a, 2001b], but the main point here is that, through the input of large-scale kinetic energy to the large-scale circulation, less mixing energy is required. Hughes and Griffiths [2006] argue that the waters that are entrained downward close to the DWF sites need not upwell to the surface before and hence can be subtracted from the mentioned $30 \mathrm{~Sv}$ of Munk and Wunsch [1998], and Gnanadesikan et al. [2005] found that the main source for gravitational potential energy is the Ekman forcing. In both cases the required amount of mixing energy is further reduced.

[128] While this picture seems plausible, there are a number of issues that need further clarification. In order to determine the terms in the mixing energy budget more precisely, from observations, a better understanding of turbulent mixing in the ocean is needed. The value for the mixing efficiency $\gamma$ (section 3.2), i.e., the part of the total turbulent kinetic energy that is available for diapycnal mixing, is still uncertain. Furthermore, the effectiveness of this mixing to enhance the potential energy of the system depends on its location. Mixing drives the overturning as long as it effectively transports heat (buoyancy) into the deep ocean. Models suggest that only the mixing in the thermocline drives a deep overturning (section 3 ) and that mixing at the boundaries is more efficient than in the ocean interior. It still needs to be verified whether locally strong mixing in regions where the thermocline is close to the bottom or the slopes (e.g., at the continental shelves) can account for the required $\kappa=1 \times 10^{-4} \mathrm{~m}^{2} \mathrm{~s}^{-1}$ averaged over the whole ocean volume.

[129] In model simulations the role of diapycnal mixing should be critically examined with a special focus on the effective mixing taking place, i.e., including numerical diffusion. While some models show a realistic AMOC with a low vertical diffusivity of $\kappa=0.1 \times 10^{-4} \mathrm{~m}^{2} \mathrm{~s}^{-1}$, many ocean models tend to operate on relatively high levels of vertical diffusivity, since the numerical diffusivity of advection schemes often is of the same order of magnitude as the explicitly set one. Moreover, mixing is often used as a tuning parameter: For example, strong mixing is applied to strengthen the AMOC and to compensate for deficiencies in the tracer distribution. As discussed above, this can lead to an unrealistic balance between the driving mechanisms of the $\mathrm{AMOC}$ and, consequently, to a possibly false representation of the climatic feedbacks.

[130] If the AMOC is largely wind driven, then this should imply a strong sensitivity of the AMOC to Southern
Ocean wind forcing. This is, however, not found in all models [Rahmstorf and England, 1997], and this sensitivity decreases with increasing model resolution [Hallberg and Gnanadesikan, 2007], because the regional, eddy-driven Deacon cell recirculation strengthens.

[131] We have emphasized that surface buoyancy forcing per se cannot sustain a steady state deep overturning circulation. However, as discussed in section 6, the distribution of surface heat and freshwater fluxes is linked with the location of deepwater formation and therefore substantially influences the transient behavior of the overturning. Evidence from the past as well as model simulations shows that changes in the surface fluxes can strongly affect the AMOC, including a general weakening or a reorganization of the associated current systems, with potentially drastic climatic impacts (section 6.4). However, the formation processes of NADW and especially of AABW are not represented in a satisfying way in most current coupled climate models. This results in diverging scenarios for future regional changes of the AMOC. Hence a more detailed implementation of DWF in models is required.

[132] The stability of the AMOC as portrayed by the Stommel [1961] bifurcation is still valid for the mixingdriven part of the AMOC. This includes the sensitivity of the AMOC to surface buoyancy fluxes. The Stommel hysteresis loop is reproduced by coupled climate models [Rahmstorf et al., 2005], and many three-dimensional ocean models show the linear scaling of the overturning with the north-south density difference implied by the Stommel model. Yet, if spurious large mixing coefficients in OGCMs are reduced, the Stommel hysteresis loop seems to shrink. For the wind-driven part of the AMOC the role of the surface fluxes is portrayed by the pump-and-valve concept of Samelson [2004], where the wind-driven upwelling is the pump and the surface buoyancy fluxes are the valve. Shutting the valve in the northern North Atlantic suppresses DWF there, but the DWF will have to happen elsewhere. If we assume that the AMOC is driven by diapycnal mixing as well as by wind-driven upwelling and is subject to surface buoyancy fluxes, then its stability behavior is determined by all these processes.

[133] In conclusion, we find that further research about both the driving processes and the deepwater formation processes is necessary to understand the AMOC and to represent it adequately in ocean and climate models. Beyond the scientific challenge itself these research efforts are indispensable to reliably assess how the ocean circulation will change in the future and what consequences this may have for the global climate.

[134] ACKNOWLEDGMENTS. We are grateful to Miguel A. M. Maqueda for contributing many relevant ideas and for many discussions from which the paper has gained strongly. We are as well indebted to Andrey Ganopolski for many useful comments and suggestions that have improved this manuscript. The paper was considerably improved by the remarks of Wilbert Weijer and two anonymous reviewers. The authors appreciate the support of several funding agencies (T.K., German Federal Ministry for Education, Science and Research through the project "Integration"; A.G. and 
M.H., McDonnell Foundation; M.M., Spanish Ministry for Science and Education through the Ramón y Cajal Program and project CGL2005-06097/CLI; and A.L., Gary Comer Foundation).

[135] The Editor responsible for this paper was Henk Dijkstra. He thanks technical reviewer Wilbert Weijer and two anonymous reviewers.

\section{REFERENCES}

Alford, M. H. (2003), Improved global maps and 54-year history of wind work on ocean inertial motions, Geophys. Res. Lett., 30(8), 1424, doi:10.1029/2002GL016614.

Alley, R., and P. Clark (1999), The deglaciation of the Northern Hemisphere: A global perspective, Annu. Rev. Earth Planet. Sci., 27, 149-182.

Arneborg, L. (2002), Mixing efficiencies in patchy turbulence, J. Phys. Oceanogr., 32, 1496-1506.

Bacon, S., W. J. Gould, and Y. Jia (2003), Open-ocean convection in the Irminger Sea, Geophys. Res. Lett., 30(5), 1246, doi:10.1029/2002GL016271.

Baines, P., and S. Condie (1998), Observations and modelling of Antarctic downslope flows: A review, in Ocean, Ice, and Atmosphere: Interactions at the Antarctic Continental Margin, Antarct. Res. Ser., vol. 75, edited by S. S. Jacobs and R. F. Weiss, pp. 29-49, AGU, Washington, D. C.

Bauer, E., A. Ganopolski, and M. Montoya (2004), Simulation of the cold climate event 8200 years ago by meltwater outburst from Lake Agassiz, Paleoceanography, 19, PA3014, doi:10.1029/2004PA001030.

Beardsley, R. C., and J. F. Festa (1972), A numerical model of convection driven by a surface stress and non-uniform horizontal heating, J. Phys. Oceanogr., 2, 444-455.

Bjerknes, V. (1916), Über thermodynamische Maschinen, die unter Mitwirkung der Schwerkraft arbeiten, Abh. Akad. Wissensch. Leipzig, 35(1), 1-33.

Bond, G., et al. (1992), Evidence for massive discharge of icebergs into the North Atlantic ocean during the last glacial, Nature, 360 , 245-249.

Braun, H., M. Christl, S. Rahmstorf, A. Ganopolski, A. Mangini, C. Kubatzki, K. Roth, and B. Kromer (2005), Solar forcing of abrupt glacial climate change in a coupled climate system model, Nature, 438, 208-211.

Brix, H., and R. Gerdes (2003), North Atlantic Deep Water and Antarctic Bottom Water: Their interaction and influence on the variability of the global ocean circulation, J. Geophys. Res. 108(C2), 3022, doi:10.1029/2002JC001335.

Broecker, W., and T.-H. Peng (1982), Tracers in the Sea, LamontDoherty Earth Obs., Palisades, N. Y.

Broecker, W., S. Sutherland, and T. Peng (1999), A possible 20th century slowdown of Southern Ocean deep water formation, Science, 286, 1132-1135.

Bryan, F. (1986), High-latitude salinity effects and interhemispheric thermohaline circulations, Nature, 323, 301-304.

Bryan, F. (1987), On the parameter sensitivity of primitive equation ocean general circulation models, J. Phys. Oceanogr., 17, 970-985.

Bryan, K., and M. Cox (1967), A numerical investigation of the oceanic general circulation, Tellus, 19, 54-80.

Bryan, K., and L. Lewis (1979), A water mass model of the world ocean, J. Geophys. Res., 84, 2503-2518.

Buffoni, G., A. Cappelletti, and P. Picco (2002), An investigation of thermohaline circulation in Terra Nova Bay polynya, Antarct. Sci., 14(1), 83-92.

Caldwell, D., and J. Moum (1995), Turbulence and mixing in the ocean, U.S. Natl. Rep. Int. Union Geod. Geophys. 1991-1994, Rev. Geophys., 33, 1385-1394.

Clark, P. U., N. G. Pisias, T. F. Stocker, and A. J. Weaver (2002), The role of the thermohaline circulation in abrupt climate change, Nature, 415, 863-869.
Colin de Verdière, A. (1988), Buoyancy driven planetary flows, J. Mar. Res., 46, 215-265.

Colin de Verdière, A. (1993), On the oceanic thermohaline circulation, in Modelling Climate-Ocean Interactions, NATO ASI Ser., Ser. I, vol. 12, edited by J. Willebrand and D. Anderson, pp. 151183, Springer, New York.

Coman, M. A., R. W. Griffiths, and G. O. Hughes (2006), Sandström's experiments revisited, J. Mar. Res., 64, 783-796.

Cubasch, U., et al. (2001), Projections of future climate change, in Climate Change 2001: The Scientific Basis: Contribution of Working Group I to the Third Assessment Report of the IPCC, edited by J. T. Houghton et al., chap. 9, pp. 525-582, Cambridge Univ. Press, New York.

Cummins, P., G. Holloway, and A. Gargett (1990), Sensitivity of the GFDL ocean general circulation model to a parameterization of vertical diffusion, J. Phys. Oceanogr., 20, 817-830.

DeBoer, A., and D. Nof (2004a), The Bering Strait's grip on the Northern Hemisphere climate, Deep Sea Res., Part I, 51, 1347-1366.

DeBoer, A., and D. Nof (2004b), The exhaust valve of the North Atlantic, J. Clim., 17, 417-422.

Defant, A. (1929), Dynamische Ozeanographie, 222 pp., Springer, New York.

Defant, A. (1961), Physical Oceanography, vol. 1, 729 pp., Elsevier, New York.

Dickson, R. R., and J. Brown (1994), The production of North Atlantic Deep Water: Sources, rates and pathways, J. Geophys. Res., 99, 12,319-12,341.

Döös, K., and A. Coward (1997), The Southern Ocean as the major upwelling zone of North Atlantic Deep Water, Int. WOCE Newsl., 27, 3-4.

Döös, K., and D. J. Webb (1994), The Deacon cell and the other meridional cells of the Southern Ocean, J. Phys. Oceanogr., 24, $429-442$.

Dutton, J. A. (1986), The Ceaseless Wind: An Introduction to the Theory of Atmospheric Motion, 617 pp., Dover, Mineola, N. Y. Egbert, G., and R. Ray (2000), Significant dissipation of tidal energy in the deep ocean inferred from satellite altimeter data, Nature, 405, 775-778.

Faller, A. J. (1968), Sources of energy for the ocean circulation and a theory of the mixed layer, in Proceedings of the Fifth United States Congress of Applied Mechanics, American Society of Mechanical Engineers, pp. 651-672, U. of Minn., Minneapolis.

Fofonoff, N. P. (1981), The gulf stream system, in Evolution of Physical Oceanography, edited by B. A. Warren and C. Wunsch, pp. 112-139, MIT Press, Cambridge, Mass.

Furevik, T., C. Mauritzen, and R. Ingvaldsen (2007), The flow of Atlantic Water to the Nordic Seas and Arctic Ocean, in Arctic Alpine Ecosystems and People in a Changing Environment, edited by J. B. Ørbæk et al., Springer, New York.

Gade, H. G., and K. E. Gustafsson (2004), Application of classical thermodynamical principles to the study of the oceanic overturning circulation, Tellus, Ser. A, 56, 371-386.

Ganachaud, A., and C. Wunsch (2000), Improved estimates of global ocean circulation, heat transport and mixing from hydrographic data, Nature, 408, 453-456.

Ganopolski, A., and S. Rahmstorf (2001a), Rapid changes of glacial climate simulated in a coupled climate model, Nature, 409, 153-158. Ganopolski, A., and S. Rahmstorf (2001b), Stability and variability of the thermohaline circulation in the past and future: A study with a coupled model of intermediate complexity, in The Oceans and Rapid Climate Change: Past, Present, and Future, Geophys. Monogr. Ser., vol. 126, edited by D. Seidov, B. J. Haupt, and M. Maslin, pp. 261-275, AGU, Washington, D. C. Ganopolski, A., V. Petoukhov, S. Rahmstorf, V. Brovkin, M. Claussen, A. Eliseev, and C. Kubatzki (2001), CLIMBER2: A climate system model of intermediate complexity. part II: Model sensitivity, Clim. Dyn., 17, 735-751.

Garabato, A. C. N., K. I. C. Oliver, A. J. Watson, and M.-J. Messias (2004a), Turbulent diapycnal mixing in the Nordic Seas, J. Geophys. Res., 109, C12010, doi:10.1029/2004JC002411. 
Garabato, A. C. N., K. L. Polzin, B. A. King, K. J. Heywood, and M. Visbeck (2004b), Widespread intense turbulent mixing in the Southern Ocean, Science, 303, 210-213.

Garrett, C., and W. Munk (1972), Space-time scales of internal waves, Geophys. Astrophys. Fluid Dyn., 2, 225-264.

Garrett, C., and W. Munk (1975), Space-time scales of internal waves: A progress report, J. Geophys. Res., 80, 291-297.

Garrett, C., and L. St. Laurent (2002), Aspects of deep ocean mixing, J. Phys. Oceanogr., 58, 11-24.

Garrett, C., P. MacCready, and P. Rhines (1993), Boundary mixing and arrested Ekman layers: Rotating stratified flow near a sloping boundary, Annu. Rev. Fluid Mech., 25, 291-323.

Gent, P., and J. McWilliams (1990), Isopycnal mixing in ocean circulation models, J. Phys. Oceanogr., 20, 150-155.

Gerdes, R., C. Köberle, and J. Willebrand (1991), The influence of numerical advection schemes on the results of ocean general circulation models, Clim. Dyn., 5, 211-226.

Gill, A., S. Green, and A. Simmons (1974), Energy partition in the large-scale ocean circulation and the production of mid-ocean eddies, Deep Sea Res. Oceanogr. Abstr., 21, 499-528.

Gill, A. E. (1982), Atmosphere-Ocean Dynamics, 662 pp, Elsevier, New York.

Gnanadesikan, A. (1999), A simple predictive model for the structure of the oceanic pycnocline, Science, 283, 2077-2079.

Gnanadesikan, A., and R. W. Hallberg (2002), Physical oceanography: Thermal structure and general circulation, Encycl. Phys. Sci. Technol., 12, 189-210.

Gnanadesikan, A., and R. J. Toggweiler (1999), Constraints by silicon cycling on vertical exchange in general circulation models, Geophys. Res. Lett., 26, 1865-1868.

Gnanadesikan, A., R. Slater, P. S. Swath, and G. K. Vallis (2005), The energetics of ocean heat transport, J. Clim., 18, 2604-2616.

Goosse, H., H. Renssen, F. M. Selten, R. J. Haarsma, and J. D. Opsteegh (2002), Potential causes of abrupt climate events: A numerical study with a three-dimensional climate model, Geophys. Res. Lett., 29(18), 1860, doi:10.1029/2002GL014993.

Gregg, M., T. Sanford, and D. Winkel (2003), Reduced mixing from the breaking of internal waves in equatorial waters, Nature, $422,513-515$.

Gregory, J. M., et al. (2005), A model intercomparison of changes in the Atlantic thermohaline circulation in response to increasing atmospheric $\mathrm{CO}_{2}$ concentration, Geophys. Res. Lett., 32, L12703, doi:10.1029/2005GL023209.

Griesel, A., and M. M. Maqueda (2006), The relation of meridional pressure gradients to North Atlantic Deep Water volume transport in an ocean general circulation model, Clim. Dyn., 26, 781799.

Griffies, S., R. Pacanowski, and R. Hallberg (2000), Spurious diapycnal mixing associated with advection in a $\mathrm{Z}$-coordinate ocean model, Mon. Weather Rev., 128, 538-564.

Hall, M., and H. Bryden (1982), Direct estimates and mechanisms of ocean heat transport, Deep Sea Res., Part A, 29, 339359.

Hallberg, R., and A. Gnanadesikan (2007), The role of eddies in determining the structure and response of the wind-driven Southern Hemisphere overturning: Results from the modeling eddies in the Southern Ocean project, J. Phys. Oceanogr., 36, 22322252.

Hasumi, H., and N. Suginohara (1999), Effects of locally enhanced vertical diffusivity over rough bathymetry on the world ocean circulation, J. Geophys. Res., 104(23), 23,367-23,374.

Heinrich, H. (1988), Origin and consequences of cyclic ice rafting in the northeast Atlantic Ocean during the past 130,000 years, Quat. Res., 29, 143-152.

Hemming, S. (2004), Heinrich events: Massive late Pleistocene detritus layers of the North Atlantic and their global climate imprint, Rev. Geophys., 42, RG1005, doi:10.1029/ 2003RG000128.

Hofmann, M., and M. Morales-Maqueda (2006), Performance of a second-order moments advection scheme in an ocean general circulation model, J. Geophys. Res., 111, C05006, doi:10.1029/2005JC003279.

Hogg, N., and W. Owens (1999), Direct measurement of the deep circulation within the Brazil Basin, Deep Sea Res., Part II, 46, 335-353.

Hogg, N., W. Owens, G. Siedler, and W. Zenk (1996), Circulation in the deep Brazil Basin, in The South Atlantic: Present and Past Circulation, edited by G. Wefer et al., pp. 249-260, Springer, New York.

Holland, W. R. (1975), Energetics of baroclinic oceans, in Numerical Models of Ocean Circulation, pp. 168-177, Natl. Acad. Press, Washington, D. C.

Houghton, J. T. (1986), The Physics of Atmospheres, 2nd ed., Cambridge Univ. Press, New York.

Huang, R. X. (1999), Mixing and energetics of the oceanic thermohaline circulation, J. Phys. Oceanogr., 29, 727-746. (Corrigendum, J. Phys. Oceanogr., 32, 1593, 2002)

Huang, R. X. (2004), Ocean, energy flows, in Encyclopedia of Energy, vol. 4, edited by C. J. Cleveland, pp. 497-509, Elsevier, New York.

Huang, R. X., and W. Wang (2003), Gravitational potential energy sinks in the oceans, in Near-Boundary Processes and Their Parameterization, Proceedings, 'Aha Huliko'a Hawaii Winter Workshop, University of Hawaii at Manoa, January 21-24, 2003, edited by P. Muller and D. Henderson, pp. 239-247, Univ. of Hawaii, Manoa.

Huang, R. X., W. Wang, and L. L. Liu (2006), Decadal variability of wind energy input into the world ocean, Deep Sea Res., Part II, 53, 31-41.

Hughes, G. O., and R. W. Griffiths (2006), A simple convective model of the global overturning circulation, including effects of entrainment into sinking regions, Ocean Modell., 12, 46-79.

Hughes, T., and A. Weaver (1994), Multiple equilibria of an asymmetric two-basin model, J. Phys. Oceanogr., 24, 619-637.

Ivchenko, V., A. Treguier, and S. Best (1997), A kinetic energy budget and internal instabilities of the Fine Resolution Antarctic Model, J. Phys. Oceanogr., 27, 5-22.

Jeffreys, H. (1925), On fluid motions produced by differences of temperature and humidity, Q.J.R. Meteorol. Soc., 51, 347-356.

Jenkins, W. (1980), Tritium and ${ }^{3} \mathrm{He}$ in the Sargasso Sea, J. Mar. Res., 38, 533-569.

Joyce, T. M., and K. G. Speer (1987), Modeling the large-scale influence of geothermal source on abyssal flow, J. Geophys. Res., 92, 2843-2850.

Kamenkovich, I., and E. Sarachik (2004), Mechanisms controlling the sensitivity of the Atlantic thermohaline circulation to the parameterization of eddy transports in ocean GCMs, J. Phys. Oceanogr., 34, 1628-1647.

Kantha, L., and C. Clayson (2000), Small Scale Processes in Geophysical Fluid Flows, Int. Geophys. Ser, vol. 67, 888 pp., Elsevier, New York.

Keeling, R. (2002), On the freshwater forcing of the thermohaline circulation in the limit of low diapycnal mixing, J. Geophys. Res., 107(C7), 3077, doi:10.1029/2000JC000685.

Keigwin, L., and E. Boyle (2000), Detecting Holocene changes in thermohaline circulation, Proc. Natl. Acad. Sci. U.S.A., 97, $1343-1346$.

Keigwin, L., W. Curry, S. Lehman, and S. Johnsen (1994), The role of the deep ocean in North Atlantic climate change between 70 and 130 kyr ago, Nature, 371, 323-326.

Key, R., et al. (2004), A global ocean carbon climatology: Results from the Global Data Analysis Project (GLODAP), Global Biogeochem. Cycles, 18, GB4031, doi:10.1029/2004GB002247.

Khatiwala, S., P. Schlosser, and M. Visbeck (2002), Rates and mechanisms of water mass transformations in the Labrador Sea as inferred from tracer observations, J. Phys. Oceanogr., 32, 666-686.

Killworth, P. D., and M. M. Nanneh (1994), Isopycnic momentum budget of the Antarctic Circumpolar Current in the Fine Resolution Antarctic Model, J. Phys. Oceanogr., 24, 1201-1223. 
Klinger, B., S. Drijfhout, J. Marotzke, and J. Scott (2003), Sensitivity of basin-wide meridional overturning to diapycnal diffusion and remote wind forcing in an idealized Atlantic-Southern Ocean geometry, J. Phys. Oceanogr., 33, 249-266.

Klinger, B. A., and J. Marotzke (1999), Behaviour of double-hemisphere thermohaline flows in a single basin, J. Phys. Oceanogr., 29, 382-399.

Kuhlbrodt, T., S. Titz, U. Feudel, and S. Rahmstorf (2001), A simple model of seasonal open ocean convection. part II: Labrador Sea stability and stochastic forcing, Ocean Dyn., 52, 36-49.

Lab Sea Group (1998), The Labrador Sea deep convection experiment, Bull. Am. Meteorol. Soc., 79, 2033-2058.

Large, W., J. McWilliams, and S. Doney (1994), Oceanic vertical mixing: A review and a model with a nonlocal boundary layer parameterization, Rev. Geophys., 32(4), 363-403.

Ledwell, J., A. Watson, and C. Law (1993), Evidence for slow mixing across the pycnocline from an open-ocean tracer release experiment, Nature, 364, 701-703.

Ledwell, J., E. Montgomery, K. Polzin, L. St. Laurent, R. Schmitt, and J. Toole (2000), Evidence for enhanced mixing over rough topography in the abyssal ocean, Nature, 403, 179-182.

Lenderink, G., and R. J. Haarsma (1994), Variability and multiple equilibria of the thermohaline circulation associated with deepwater formation, J. Phys. Oceanogr., 24, 1480-1493.

Lenderink, G., and R. J. Haarsma (1996), Modeling convective transitions in the presence of sea ice, J. Phys. Oceanogr., 36, 1448-1467.

Levermann, A., and A. Griesel (2004), Solution of a model for the oceanic pycnocline depth: Scaling of overturning strength and meridional pressure difference, Geophys. Res. Lett., 31, L17302, doi:10.1029/2004GL020678.

Levermann, A., A. Griesel, M. Hofmann, M. Montoya, and S. Rahmstorf (2005), Dynamic sea level changes following changes in the thermohaline circulation, Clim. Dyn., 24, 347-354.

Levitus, S. (1982), Climatological atlas of the world ocean, Prof. Pap. 13, 173 pp., NOAA, Silver Spring, Md.

Lilly, J. M., P. B. Rhines, M. Visbeck, R. Davis, J. R. N. Lazier, F. Schott, and D. Farmer (1999), Observing deep convection in the Labrador Sea during winter 1994-1995, J. Phys. Oceanogr., 29, $2065-2098$

Lohmann, G., and J. Schneider (1999), Dynamics and predictability of Stommel's box model: A phase-space perspective with implications for decadal climate variability, Tellus, Ser. A, 51, 326-336.

Lueck, R., and R. Reid (1984), On the production and dissipation of mechanical energy in the ocean, J. Geophys. Res., 89, 34393445.

Luyten, J., J. Pedlosky, and H. Stommel (1983), The ventilated thermocline, J. Phys. Oceanogr., 13, 292-309.

Manabe, S., and R. J. Stouffer (1988), Two stable equilibria of a coupled ocean-atmosphere model, J. Clim., 1, 841-866.

Manabe, S., and R. J. Stouffer (1994), Multiple-century response of a coupled ocean-atmosphere model to an increase of atmospheric carbon dioxide, J. Clim., 7, 5-23.

Maqueda, M., A. Willmott, and N. Biggs (2004), Polynya dynamics: A review of observations and modeling, Rev. Geophys., 42, RG1004, doi:10.1029/2002RG000116.

Marotzke, J. (1997), Boundary mixing and the dynamics of the three-dimensional thermohaline circulation, J. Phys. Oceanogr., $27,1713-1728$

Marotzke, J., and J. Willebrand (1991), Multiple equilibria of the global thermohaline circulation, J. Phys. Oceanogr., 21, 13721385.

Marshall, J., and F. Schott (1999), Open-ocean convection: Observations, theory, and models, Rev. Geophys., 37(1), 1-64.

Marshall, J., H. Jones, R. Karsten, and R. Wardle (2002), Can eddies set ocean stratification?, J. Phys. Oceanogr., 32, 26-38.

Marzeion, B., A. Levermann, and J. Mignot (2007), The role of stratification-dependent mixing for the stability of the Atlantic overturning in a global climate model, J. Phys. Oceanogr., in press.
McManus, J., R. Francois, J.-M. Gherardi, L. Keigwin, and S. Brown-Leger (2004), Collapse and rapid resumption of Atlantic meridional circulation linked to deglacial climate changes, Nature, 428, 834-837.

Meincke, J., B. Rudels, and H. J. Friedrich (1997), The Arctic Ocean Nordic Seas thermohaline system, J. Mar. Sci., 54(3), 283-299.

Mignot, J., A. Levermann, and A. Griesel (2006), A decomposition of the Atlantic meridional overturning circulation into physical components using its sensitivity to vertical mixing, J. Phys. Oceanogr., 36, 636-650.

Mohammad, R., and J. Nilsson (2004), The role of diapycnal mixing for the equilibrium response of the thermohaline circulation, Ocean Dyn., 54, 54-65.

Monahan, A. H. (2002), Stabilisation by noise of climate regimes in a simple model: Implications for stability of the thermohaline circulation, J. Phys. Oceanogr., 32, 2072-2085.

Montoya, M., A. Griesel, A. Levermann, J. Mignot, M. Hofmann, A. Ganopolski, and S. Rahmstorf (2005), The Earth system model of intermediate complexity CLIMBER-3 $\alpha$. part I: Description and performance for present day conditions, Clim. Dyn., 25, 237-263.

Morel, A., and D. Antoine (1994), Heating rate within the upper ocean in relation to its bio-optical state, J. Phys. Oceanogr., 24, $1652-1665$

Moum, J., and T. Osborn (1986), Mixing in the main thermocline, J. Phys. Oceanogr., 16, 1250-1259.

Moum, J., D. Caldwell, J. Nash, and G. Gunderson (2002), Observations of boundary mixing over the continental slope, J. Phys. Oceanogr., 32, 2113-2130.

Mullarney, J. C., R. W. Griffiths, and G. O. Hughes (2004), Convection driven by differential heating at a horizontal boundary, J. Fluid Mech., 516, 181-209.

Munk, W. (1966), Abyssal recipes I, Deep Sea Res. Oceanogr. Abstr., 13, 707-730.

Munk, W. (1981), Internal waves and small-scale processes, in Evolution of Physical Oceanography, edited by B. Warren and C. Wunsch, pp. 264-291, MIT Press, Cambridge, Mass.

Munk, W., and C. Wunsch (1998), Abyssal recipes II: Energetics of tidal and wind mixing, Deep Sea Res., Part I, 45, 1977-2010. Neumann, G., and W. Pierson (1966), Principles of Physical Oceanography, 545 pp., Prentice-Hall, Upper Saddle River, N. J.

Nilsson, J., and G. Walin (2001), Freshwater forcing as a booster of the thermohaline circulation, Tellus, Ser. A, 53, 629-641.

Nilsson, J., G. Brostroem, and G. Walin (2003), The thermohaline circulation and vertical mixing: Does weaker density stratification give stronger overturning?, J. Phys. Oceanogr., 33, 27812795.

Nof, D. (2000), Does the wind control the import and export of the South Atlantic?, J. Phys. Oceanogr., 30, 2650-2667.

Nof, D. (2003), The Southern Ocean's grip on the northward meridional flow, Prog. Oceanogr., 56, 223-247.

Oakey, N., B. Ruddick, D. Walsh, and J. Burke (1994), Turbulence and microstructure measurements during North Atlantic Tracer Release Program, Eos Trans. AGU, 75(3), Ocean Sci. Meet. Suppl., 130.

Oort, A., L. Anderson, and J. Peixoto (1994), Estimates of the energy cycle of the oceans, J. Geophys. Res., 99, 7665-7688.

Orsi, A., G. Johnson, and J. Bullister (1999), Circulation, mixing, and production of Antarctic Bottom Water, Prog. Oceanogr., 43, $55-109$.

Osborn, T. (1980), Estimates of the local rate of vertical diffusion from dissipation measurements, J. Phys. Oceanogr., 10, 83-89.

Paparella, F., and W. R. Young (2002), Horizontal convection is non-turbulent, J. Fluid Mech., 466, 205-214.

Park, Y.-G. (1999), The stability of thermohaline circulation in a two-box model, J. Phys. Oceanogr., 29, 3101-3110.

Park, Y.-G., and K. Bryan (2000), Comparison of thermally driven circulations from a depth-coordinate model and an isopycnal- 
layer model. part I: Scaling-law sensitivity to vertical diffusivity, J. Phys. Oceanogr., 30, 590-605.

Peltier, W., and C. Caulfield (2003), Mixing efficiency in stratified shear flows, Annu. Rev. Fluid Mech., 35, 135-167.

Pickart, R. S., M. A. Spall, M. H. Ribergaard, G. W. K. Moore, and R. F. Milliff (2003), Deep convection in the Irminger Sea forced by the Greenland tip jet, Nature, 424, 152-156.

Pierce, D. W., T. P. Barnett, and U. Mikolajewicz (1995), Competing roles of heat and freshwater flux in forcing thermohaline oscillations, J. Phys. Oceanogr., 25, 2046-2064.

Polzin, K., J. Toole, J. Ledwell, and R. Schmitt (1997), Spatial variability of turbulent mixing in the abyssal ocean, Science, 276, 93-96.

Prange, M., G. Lohmann, and A. Paul (2003), Influence of vertical mixing on the hysteresis: Analysis of an OGCM, J. Phys. Oceanogr., 33, 1707-1721.

Radko, T., and J. Marshall (2004), Eddy-induced diapycnal fluxes and their role in the maintenance of the thermocline, J. Phys. Oceanogr., 34, 372-383.

Rahmstorf, S. (1994), Rapid climate transitions in a coupled oceanatmosphere model, Nature, 372, 82-85.

Rahmstorf, S. (1995a), Bifurcations of the Atlantic thermohaline circulation in response to changes in the hydrological cycle, Nature, 378, 145-149.

Rahmstorf, S. (1995b), Multiple convection patterns and thermohaline flow in an idealized OGCM, J. Clim., 8, 3028-3039.

Rahmstorf, S. (1996), On the freshwater forcing and transport of the Atlantic thermohaline circulation, Clim. Dyn., 12, 799-811.

Rahmstorf, S. (1997), Risk of sea-change in the Atlantic, Nature, $388,825-826$.

Rahmstorf, S. (2000), The thermohaline ocean circulation: A system with dangerous thresholds?, Clim. Change, 46, 247256.

Rahmstorf, S. (2002), Ocean circulation and climate during the past 120,000 years, Nature, 419, 207-214.

Rahmstorf, S. (2003), Thermohaline circulation: The current climate, Nature, 421, 699.

Rahmstorf, S., and M. England (1997), Influence of Southern Hemisphere winds on North Atlantic Deep Water flow, J. Phys. Oceanogr., 27, 2040-2054.

Rahmstorf, S., and A. Ganopolski (1999), Long-term global warming scenarios computed with an efficient coupled climate model, Clim. Change, 43, 353-367.

Rahmstorf, S., J. Marotzke, and J. Willebrand (1999), Stability of the thermohaline circulation, in The Warm Water Sphere of the North Atlantic Ocean, edited by W. Krauss, pp. 129-158, Gebrüder Borntraeger, Stuttgart, Germany.

Rahmstorf, S., et al. (2005), Thermohaline circulation hysteresis: A model intercomparison, Geophys. Res. Lett., 32, L23605, doi:10.1029/2005GL023655.

Redi, M. (1982), Oceanic isopycnal mixing by coordinate rotation, J. Phys. Oceanogr., 12, 1154-1158.

Rhines, P. B., and S. Häkkinen (2003), Is the oceanic heat transport in the North Atlantic irrelevant to the climate in Europe?, Arct. Subarct. Ocean Fluxes Newsl., 1, 13-17.

Rintoul, S. R., C. W. Hughes, and D. Olbers (2001), The Antarctic Circumpolar Current system, in Ocean Circulation and Climate, edited by G. Siedler, pp. 271-301, Elsevier, New York.

Robbins, P. E., and J. M. Toole (1997), The dissolved silica budget as a constraint on the meridional overturning circulation of the Indian Ocean, Deep Sea Res., Part I, 44, 879-906.

Robinson, A., and H. Stommel (1959), The oceanic thermocline and the associated thermohaline circulation, Tellus, 3, 295-308.

Rooth, C. (1982), Hydrology and ocean circulation, Prog. Oceanogr., 11, 131-149.

Rossby, H. T. (1965), On thermal convection driven by non-uniform heating from below, Deep Sea Res. Oceanogr. Abstr., 12, $9-16$.

Rossby, T. (1998), Numerical experiments with a fluid heated nonuniformly from below, Tellus, Ser. A, 50, 242-257.
Saenko, O., and W. Merryfield (2005), On the effect of topographically enhanced mixing on the global ocean circulation, J. Phys. Oceanogr., 35, 826-834.

Saenko, O., and A. Weaver (2003), Southern Ocean upwelling and eddies: Sensitivity of the global overturning to the surface density range, Tellus, Ser. A, 55, 106-111.

Saenko, O. A., and A. J. Weaver (2004), What drives heat transport in the Atlantic Ocean?, Geophys. Res. Lett., 31, L20305, doi:10.1029/2004GL020671.

Samelson, R. (2004), Simple mechanistic models of middepth meridional overturning, J. Phys. Oceanogr., 34, 2096-2103.

Sandström, J. W. (1908), Dynamische Versuche mit Meerwasser, Ann. Hydrogr. Mar. Meteorol., 36, 6-23.

Sandström, J. W. (1916), Meteorologische Studien im Schwedischen Hochgebirge, Göteborgs K. Vetensk. Vitterhetssamhällets Handkl., 27, 48 pp.

Sarnthein, M., K. Winn, S. J. A. Jung, J.-C. Duplessy, L. Labeyrie, H. Erlenkeuser, and G. Ganssen (1994), Changes in east Atlantic deepwater circulation over the last 30,000 years: Eight time slice reconstructions, Paleoceanography, 9, 209-267.

Schaeffer, M., F. M. Selten, J. D. Opsteegh, and H. Goosse (2002), Intrinsic limits to predictability of abrupt regional climate change in IPCC SRES scenarios, Geophys. Res. Lett., 29(16), 1767, doi:10.1029/2002GL015254.

Schiller, A., U. Mikolajewicz, and R. Voss (1997), The stability of the North Atlantic thermohaline circulation in a coupled oceanatmosphere general circulation model, Clim. Dyn., 13, 325-347.

Schlitzer, R. (2000), Electronic atlas of WOCE hydrographic and tracer data now available, Eos Trans. $A G U, 81(5), 45$.

Schmitt, R. W. (1994), Double diffusion in oceanography, Annu. Rev. Fluid Mech., 26, 255-285.

Schmittner, A. (2005), Decline of the marine ecosystem caused by a reduction in the Atlantic overturning circulation, Nature, 434, $628-633$.

Schmittner, A., and A. Weaver (2001), Dependence of multiple climate states on ocean mixing parameters, Geophys. Res. Lett., $28,1027-1030$.

Schmitz, W. J. (1995), On the interbasin-scale thermohaline circulation, Rev. Geophys., 33(2), 151-174.

Schmitz, W. J. (1996), On the world ocean circulation, vol. II: The Pacific and Indian Oceans: A global update, Tech. Rep., WHOI96-08, 237 pp., Woods Hole Oceanogr. Inst., Woods Hole, Mass.

Scott, J. R., and J. Marotzke (2002), The location of diapycnal mixing and the meridional overturning circulation, J. Phys. Oceanogr., 32, 3578-3595.

Seager, R., D. S. Battisti, J. Yin, N. Gordon, N. Naik, A. C. Clement, and M. A. Cane (2002), Is the Gulf Stream responsible for Europe's mild winters?, Q. J. R. Meteorol. Soc., 128, $1-24$.

Severinghaus, J. P., et al. (2003), A method for precise measurement of argon 40/36 and krypton/argon ratios in trapped air in polar ice with applications to past firn thickness and abrupt climate change in Greenland and at Siple Dome, Antarctica, Geochim. Cosmochim. Acta, 67, 325-343.

Siggers, J. H., R. R. Kershwell, and N. J. Balmforth (2004), Bounds on horizontal convection, J. Fluid Mech., 517, 55-70.

Simmons, H., S. Jayne, L. St. Laurent, and A. Weaver (2004), Tidally driven mixing in a numerical model of the ocean general circulation, Ocean Modell., 6, 245-263.

Sloyan, B. M., and S. R. Rintoul (2001a), The Southern Ocean limb of the global deep overturning circulation, J. Phys. Oceanogr., 31, 143-173.

Sloyan, B. M., and S. R. Rintoul (2001b), Circulation, renewal and modification of Antarctic mode and intermediate water, J. Phys. Oceanogr., 31, 1005-1030.

Smethie, W. M., Jr., and R. A. Fine (2001), Rates of North Atlantic Deep Water formation calculated from chlorofluorocarbon inventories, Deep Sea Res., Part I, 48, 189-215.

Spall, M. J. (2004), Boundary currents and watermass transformation in marginal seas, J. Phys. Oceanogr., 34, 1197-1213. 
Speer, K., S. Rintoul, and B. Sloyan (2000), The diabatic Deacon cell, J. Phys. Oceanogr., 30, 3212-3222.

St. Laurent, L., and C. Garrett (2002), The role of internal tides in mixing the deep ocean, J. Phys. Oceanogr., 32, 2882-2899.

Stommel, H. (1961), Thermohaline convection with two stable regimes of flow, Tellus, 13, 224-230.

Stommel, H. (1962), On the smallness of sinking regions in the ocean, Proc. Natl. Acad. Sci. U.S.A., 48, 766-772.

Stommel, H., and A. B. Arons (1960), On the abyssal circulation of the world ocean - I. Stationary planetary flow patterns on a sphere, Deep Sea Res., 6, 140-154.

Stouffer, R. J., and S. Manabe (2003), Equilibrium response of thermohaline circulation to large changes in atmospheric $\mathrm{CO}_{2}$, Clim. Dyn., 20, 759-773, doi:10.1007/s00382-002-0302-4.

Straneo, F. (2006), On the connection between dense water formation, overturning and poleward heat transport in a convective basin, J. Phys. Oceanogr., 36, 1822-1840.

Talley, L., J. Reid, and P. Robbins (2003), Data-based meridional overturning streamfunctions for the global ocean, J. Clim., 16, 3213-3224.

Thompson, L., and G. Johnson (1996), Abyssal currents generated by diffusion and geothermal heating over rises, Deep Sea Res., Part I, 43, 193-211.

Thorpe, R., J. Gregory, T. Johns, R. Wood, and J. Mitchell (2001), Mechanisms determining the Atlantic thermohaline circulation response to greenhouse gas forcing in a non-flux-adjusted coupled climate model, J. Clim., 14, 3102-3116.

Timmermann, A., and H. Goosse (2004), Is the wind stress forcing essential for the meridional overturning circulation?, Geophys. Res. Lett., 31, L04303, doi:10.1029/2003GL018777.

Timmermann, A., S.-I. An, U. Krebs, and H. Goosse (2005), ENSO suppression due to weakening of the North Atlantic thermohaline circulation, J. Clim., 18, 2842-2859.

Toggweiler, J. R., and B. Samuels (1993a), Is the magnitude of the deep outflow from the Atlantic Ocean actually governed by Southern Hemisphere winds?, in The Global Carbon Cycle, NATO ASI Ser., Ser. I, edited by M. Heimann, pp. 333-366, Springer, New York.

Toggweiler, J. R., and B. Samuels (1993b), New radiocarbon constraints on the upwelling of abyssal water to the ocean's surface, in The Global Carbon Cycle., NATO ASI Ser., Ser. I, edited by M. Heimann, pp. 303-331, Springer, New York.

Toggweiler, J. R., and B. Samuels (1995), Effect of Drake Passage on the global thermohaline circulation, Deep Sea Res., Part I, 42, 477-500.

Toggweiler, J. R., and B. Samuels (1998), On the ocean's large scale circulation in the limit of no vertical mixing, J. Phys. Oceanogr., 28, 1832-1852.

Toggweiler, J. R., K. Dixon, and W. S. Broecker (1991), The Peru upwelling and the ventilation of the South Pacific thermocline, J. Geophys. Res., 96, 20,467-20,497.

Trenberth, K. E., and J. M. Caron (2001), Estimates of meridional atmosphere and ocean heat transports, J. Clim., 14, 3433-3443.

Tziperman, E., J. R. Toggweiler, Y. Feliks, and K. Bryan (1994), Instability of the thermohaline circulation with respect to mixed boundary conditions: Is it really a problem for realistic models?, J. Phys. Oceanogr., 24, 217-232.

Vallis, G. (1999), Large-scale circulation and production of stratification: Effects of wind, geometry and diffusion, J. Phys. Oceanogr., 30, 933-954.

van Kreveld, S., M. Sarnthein, H. Erlenkeuser, P. Grootes, S. Jung, M. J. Nadeau, U. Pflaumann, and A. Voelker (2000), Potential links between surging ice sheets, circulation changes, and the Dansgaard-Oeschger cycles in the Irminger Sea, 60-18 kyr, Paleoceanography, 15, 425-442.

Vellinga, M., and R. A. Wood (2002), Global climatic impacts of a collapse of the Atlantic thermohaline circulation, Clim. Change, $54,251-267$.

Veronis, G. (1975), The role of models in tracer studies, in Numerical Models of Ocean Circulation, pp. 133-146, Natl. Acad. of Sci., Washington, D. C.
Voelker, A., et al. (2002), Global distribution of centennial-scale records for marine isotope stage (MIS) 3: A database, Quat. Sci. Rev., 21, 1185-1214.

Wang, W., and R. X. Huang (2004a), Wind energy input into the Ekman layer, J. Phys. Oceanogr., 34, 1267-1275.

Wang, W., and R. X. Huang (2004b), Wind energy input into the surface waves, J. Phys. Oceanogr., 34, 1276-1280.

Wang, W., and R. X. Huang (2005), An experimental study on thermal circulation driven by horizontal differential heating, J. Fluid Mech., 540, 49-73.

Watanabe, M., and T. Hibiya (2002), Global estimates of the windinduced energy flux to inertial motions in the surface mixed layer, Geophys. Res. Lett., 29(8), 1239, doi:10.1029/ 2001 GL014422.

Watson, A. J., et al. (1999), Mixing and convection in the Greenland Sea from a tracer-release experiment, Nature, 401, 902904.

Weaver, A. J., and T. M. C. Hughes (1992), Stability and variability of the thermohaline circulation and its link to climate, in Trends in Physical Oceanography, pp. 15-70, Counc. of Sci. Res. Integr., Trivandrum, India.

Weaver, A. J., C. M. Bitz, A. F. Fanning, and M. M. Holland (1999), Thermohaline circulation: High-latitude phenomena and the difference between the Pacific and Atlantic, Annu. Rev. Earth Planet. Sci., 27, 231-285.

Webb, D. J., and N. Suginohara (2001a), Vertical mixing in the ocean, Nature, 409, 37.

Webb, D. J., and N. Suginohara (2001b), The interior circulation of the ocean, in Ocean Circulation and Climate, edited by G. Siedler, pp. 205-214, Elsevier, New York.

Welander, P. (1982), A simple heat-salt oscillator, Dyn. Atmos. Oceans, 6, 233-242.

Wood, R. A., A. B. Keen, J. F. B. Mitchell, and J. M. Gregory (1999), Changing spatial structure of the thermohaline circulation in response to atmospheric $\mathrm{CO}_{2}$ forcing in a climate model, Nature, 399, 572-575.

Wood, R. A., M. Vellinga, and R. Thorpe (2003), Global warming and thermohaline circulation stability, Philos. Trans. R. Soc. London, Ser. A, 361, 1961-1975.

Wright, D., C. Vreugdenhil, and T. Hughes (1995), Vorticity dynamics and zonally averaged ocean circulation models, J. Phys. Oceanogr., 25, 2141-2154.

Wunsch, C. (1998), The work done by the wind on the oceanic general circulation, J. Phys. Oceanogr., 28, 2332-2340.

Wunsch, C. (2005), Thermohaline loops, Stommel box models, and the Sandström theorem, Tellus, Ser. A, 57, 84-99.

Wunsch, C. (2006), Abrupt climate change: An alternative view, Quat. Res., 65, 191-203.

Wunsch, C., and R. Ferrari (2004), Vertical mixing, energy and the general circulation of the oceans, Annu. Rev. Fluid Mech., 36, $281-314$.

Wunsch, C., D. Hu, and B. Grant (1983), Mass, heat, salt and nutrient fluxes in the South Pacific Ocean, J. Phys. Oceanogr, $13,725-753$.

Zhang, J., R. Schmitt, and R. Huang (1999), The relative influence of diapycnal mixing and hydrologic forcing on the stability of the thermohaline circulation, J. Phys. Oceanogr., 29, 1096-1108.

Zickfeld, K., A. Levermann, M. Granger Morgan, T. Kuhlbrodt, S. Rahmstorf, and D. Keith (2007), Expert judgements on the response of the Atlantic meridional overturning circulation to climate change, Clim. Change, in press.

A. Griesel, Scripps Institution of Oceanography, La Jolla, CA, USA.

M. Hofmann, T. Kuhlbrodt, A. Levermann, and S. Rahmstorf, Climate System Department, Potsdam Institute for Climate Impact Research, P.O. Box 601203, D-14412 Potsdam, Germany. (kuhlbrodt@ pik-potsdam.de)

M. Montoya, Departamento Astrofisica y Ciencias de la Atmósfera, Facultad de Ciencias Físicas, Universidad Complutense de Madrid, 28040 Madrid, Spain. 